\title{
ПРАКТИЧЕСКИЕ РЕКОМЕНДАЦИИ ПО ЛЕКАРСТВЕННОМУ ЛЕЧЕНИЮ РАКА ПРЯМОЙ КИШКИ
}

Коллектив авторов: Федянин М.Ю., Артамонова Е.В., Барсуков Ю.А., Болотина Л.В., Гладков О.А., Глебовская В.В., Гордеев С.С., Карачун А.М., Козлов Н.А., Любченко Л.Н., Малихова О.А., Мамедли 3.3., Михайлов А.И., Подлужный Д.В., Проценко С.А., Рыбаков Е.Г., Рыков И.В., Самсонов Д.В., Сидоров Д.В., Снеговой А.В., Ткачёв С.И., Трякин А.А., Цуканов А.С., Черных М.В., Шелыгин Ю.А.

DOI: $10.18027 / 2224-5057-2020-10-3 s 2-23$

Ключевые слова: рак прямой кишки, химиотерапия, таргетная терапия, хирургия, метастазэктомия

\section{1. КЛАССИФИКАЦИЯ И ОПРЕДЕЛЕНИЕ СТАДИИ}

Гистологическая классификация рака прямой кишки (РПК) проводится в соответствии с международной классификацией опухолей от 2019 г.

\section{1. Международная гистологическая классификация (В03, 2019 г.)}

\section{Эпителиальные опухоли}

І. Доброкачественные опухоли
a. 8211/0 Тубулярная аденома
b. $8261 / 0$ Ворсинчатая аденома
c. 8263/0 Тубулярно-ворсинчатая аденома
d. 8220/0 Аденоматозный полип
е. 8213/0 Зубчатая дисплазия

II. Интраэпителиальная неоплазия (дисплазия), связанная с хроническими воспалительными заболеваниями кишечника

а. 8148/2 Железистая интраэпителиальная неоплазия высокой степени

b. 8148/0 Железистая интраэпителиальная неоплазия низкой степени

Цитирование: Федянин М.Ю., Гладков О.А., Гордеев С.С., Трякин А.А., Черных М.В. и соавт. Практические рекомендации по лекарственному лечению рака прямой кишки. Злокачественные опухоли: Практические рекомендации RUSSCO \#3s2, 2020 (том 10).23 
III. Pak

a. 8140/3 Аденокарцинома БДУ

b. $8213 / 3$ Зубчатая аденокарцинома²

c. 8262/3 Аденомо-подобная аденокарцинома ${ }^{3}$

d. 8265/3 Микропапиллярная аденокарцинома

е. $8480 / 3$ Муцинозная (слизистая) аденокарцинома ${ }^{4}$

f. $8490 / 3$ Рак с диффузным типом роста ${ }^{5}$

g. 8490/3 Перстневидноклеточный рак 6

h. 8560/3 Железисто-плоскоклеточный рак

i. $8510 / 3$ Медуллярный рак

j. $8220 / 3$ Недифференцированный рак Бду8

k. 8033/3 Рак с саркоматоидным компонентом ${ }^{9}$

l. 8240/3 Нейроэндокринная опухоль БДУ

m. 8240/3 Нейроэндокринная опухоль G1

n. 8249/3 Нейроэндокринная опухоль G2

о. 8249/3 Нейроэндокринная опухоль G3

p. $8246 / 3$ Нейроэндокринный рак Бду10

q. 8041/3 Мелкоклеточный рак

r. 8013/3 Крупноклеточный нейроэндокринный рак

1 Аденокарцинома кишечного типа, без дополнительного уточнения. По степени дифференцировки (с соответствием степени злокачественности) опухоли делятся на высокодифференцированные/G1 (96$100 \%$ эпителиальных элементов инвазивной опухоли представлены железистыми структурами), умеренно дифференцированные/G2 (50-95\% эпителиальных элементов инвазивной опухоли представлено железистымu структурамU), низкодифференцированные/G3 (0-49\% эпителиальных элементов инвазивной опухоли представлены железистыми структурами).

2 При правосторонней локализации опухоль часто ассоциирована с MSI-H.

3 Нозологическая единица впервые введена комитетом IARC/WHO в МКБ-О в 2019 г.

4 Устанавливается, если $>50 \%$ объёма опухоли представлено внеклеточной слизью, допустимо наличие перстневидноклеточных элементов (<50\% от всех клеток инвазивной опухоли). Оченка степени дифферецировки аналогична типичной аденокарциноме. При правосторонней локализации опухоль часто ассоциирована с MSI-H.

5 Опухоль всегда соответствует G3.

6 Устанавливается, если $>50 \%$ клеток опухоли представлено перстневидноклеточными элементами. Опухоль всегда соответствует G3. При правосторонней локализации опухоль часто ассоциирована с MSI-H.

7 Опухоль всегда coответствует G3. При правосторонней локализации опухоль часто ассоциирована C MSI-H.

8 Является диагнозом исключения - устанавливается только по результатам применения дополнительных методов исследования (иммуногистохимия, электронная микроскопия), соответствует G4.

9 Нозологическая единица впервые введена комитетом IARC/WHO в МКБ-О в 2019 г. Является диагнозом исключения, соответствует G3-G4.

10 Диагноз устанавливается только по результатам применения дополнительных методов исследования (иммуногистохимия, электронная микроскопия), всегда соответствует G3. 
s. 8154/3 Смешанное нейроэндокринное-ненейроэндокринное новообразование ${ }^{1}$

Согласно Классификации ВОЗ (2019 г.), гистологическая градация аденокарциномы / рака (исключая нейроэндокринные новообразования) толстой кишки:

- становится 2-ступенчатой вместо ранее используемой 4-ступенчатой: низкая степень злокачественности (включает карциномы G1 - G2), высокая степень злокачественности (включает карциномы G3-G4);

- осуществляется на основании подсчета доли железистых структур в инвазивной опухоли (игнорируются мелкие кластеры и отдельные клетки инвазивного фронта);

- в случае неоднородного строения опухоли оценка проводится по наименее дифферецированному компоненту (игнорируются мелкие кластеры и отдельные клетки инвазивного фронта);

- в целях преемственности рекомендуется временно указывать оба показателя (например, аденокарцинома низкой степени злокачественности (G2)).

\section{2. Стадирование}

\subsection{1. Стадирование рака прямой кишки по системе TNM-8 (2017 г.)}

Для рака ободочной и прямой кишки используется единая классификация. Символ Т содержит следующие градации:

TX - недостаточно данных для оценки первичной опухоли

Tis - преинвазивный рак (интраэителиальная инвазия или инвазия собственной пластинки слизистой оболочки)

T1 - опухоль распространяется в подслизистый слой стенки кишки

т2 - опухоль распространяется на мышечный слой, без прорастания стенки кишки

T3 - опухоль прорастает все слои стенки кишки с распространением в жировую клетчатку, без поражения соседних органов.

Для опухолей, расположенных в верхнеампулярном отделе прямой кишки и ректосигмоидном отделах толстой кишки (покрытых брюшиной), символ Т3 характеризует распространение опухоли до субсерозной оболочки (не прорастают серозную оболочку).

T4 - опухоль прорастает в окружающие органы и ткани или серозную оболочку при локализации в верхнеампулярном отделе прямой кишки и ректосигмоидном отделах толстой кишки (покрытых брюшиной) T4a - прорастание висцеральной брюшины T4b - прорастание в другие органы и структуры.

1 Диагноз устанавливается только по результатам применения дополнительных методов исследования; является диморфным раком, сочетающим компоненты аденокарциномы и нейроэндокринного рака/опухоли (доля любого компонента должна быть не менее 30\%). 
Символ N указывает на наличие или отсутствие метастазов в регионарных лимфатических узлах.

$\mathbf{N X}$ - недостаточно данных для оценки регионарных лимфатических узлов

NO - поражения регионарных лимфатических узлов нет

N1 - метастазы в 1-3 (включительно) регионарных лимфатических узлах N1a - метастазы в 1 регионарном лимфатическом узле

N1b - метастазы в 2-3 лимфатических узлах

N1c - диссеминаты в брыжейке без поражения регионарных лимфатических узлов

$\mathbf{N 2 ~ - ~ м е т а с т а з ы ~ б о л е е ~ ч е м ~ в ~} 3$ регионарных лимфатических узлах

$\mathbf{N 2 a}$-поражены 4-6 лимфатических узлов

$\mathbf{N 2 b}$-поражены 7 и более лимфатических узлов.

Символ М характеризует наличие или отсутствие отдаленных метастазов.

м0 - отдаленных метастазов нет

M1 - наличие отдаленных метастазов

M1a - наличие отдаленных метастазов в одном органе

M1b - наличие отдаленных метастазов более чем в одном органе

M1с - метастазы по брюшине.

Группировка по стадиям представлена в табл. 1:

Таблица 1. Стадии рака толстой кишки

\begin{tabular}{|l|l|l|l|}
\hline Стадия & $\mathrm{T}$ & $\mathrm{N}$ & $\mathrm{M}$ \\
\hline $\mathrm{O}$ & is & 0 & 0 \\
\hline $\mathrm{I}$ & 1,2 & 0 & 0 \\
\hline $\mathrm{II}$ & 3,4 & 0 & 0 \\
\hline IIA & 3 & 0 & 0 \\
\hline IIB & $4 \mathrm{a}$ & 0 & 0 \\
\hline IIC & $4 \mathrm{~b}$ & 0 & 0 \\
\hline III & Любая & 1,2 & 0 \\
\hline IIIA & 1,2 & 1 & 0 \\
& 1 & $2 \mathrm{a}$ & 0 \\
\hline IIIB & $3,4 a$ & 1 & 0 \\
& 2,3 & $2 \mathrm{a}$ & 0 \\
\hline IIIC & $4 \mathrm{~b}$ & $1,2 \mathrm{a}, 2 \mathrm{~b}$ & 0 \\
& $4 a$ & $2 \mathrm{a}$ & 0 \\
\hline IV & $3,4 a$ & $2 \mathrm{~b}$ & 0 \\
\hline IVa & Любая & Любая & 1 \\
\hline IVb & Любая & Любая & $1 \mathrm{a}$ \\
\hline IVc & Любая & Любая & $1 \mathrm{~b}$ \\
\hline
\end{tabular}




\subsection{2. Стадирование по Kikuchi раннего рака прямой кишки}

При планировании местного иссечения Т1 РПК предлагается детальное стадирование заболевания на основании данных МРТ и УЗ-колоноскопии по следующим критериям:

T1sm1 - глубина инвазии подслизистого слоя до 1/3.

T1sm2 - умеренная глубина инвазии подслизистого слоя - до 2/3

T1sm3 - полная инвазия опухолью всего подслизистого слоя.

Окончательное стадирование проводится по результатам гистологического исследования после удаления опухоли.

\subsection{3. МРТ-подклассификация ТЗ рака прямой кишки}

Для персонализации показаний к предоперационному лечению ТЗ рака прямой кишки используется основанная на данных МРТ дополнительная классификация [16]:

T3а - инвазия в мезоректальную клетчатку менее 1 мм

T3b - инвазия в мезоректальную клетчатку 1-5 мм

T3с - инвазия в мезоректальную клетчатку 5-15 мм

T3d - инвазия в мезоректальную клетчатку более 15 мм.

\section{2. ДИАГНОСТИКА}

Диагноз РПК основывается на данных осмотра, результатах инструментальных методов обследования и патоморфологическом заключении.

\section{1. Жалобы и анамнез}

Необходимо проводить сбор жалоб и анамнеза у пациента с целью выявления факторов, которые могут повлиять на выбор тактики лечения. У 3-5\% больных раком ободочной кишки развитие заболевания связано с наличием известных наследственных синдромов. Наиболее распространённые - синдром Линча, семейный аденоматоз толстой кишки и MutYH-ассоциированный полипоз. В связи с этим у всех больных колоректальным раком рекомендуется собрать семейный анамнез и проанализировать его на соответствие критериям Amsterdam II, Bethesda и критериев ГНЦК им. А.Н. Рыжих (приложение A).

Соответствие критериям Amsterdam - показание для направления на консультацию генетика и генетическое тестирование. Соответствие рекомендациям Bethesda - показание для тестирования на микросателлитную нестабильность (MSI). При выявлении MSI-H показано направление к генетику, генетическое тестирование. Однако в РФ до 25-30\% пациентов с генетически подтвержденным синдромом Линча не соответствуют критериям Амстердам, поскольку у них отсутствует отягощенный семейный анамнез. В этой связи для отбора российских пациентов с подозрением на синдром Линча были 
разработаны оригинальные критерии (приложение A), которые учитывают их популяционные особенности. Соответствие рекомендациям - показание для тестирования на MSI. При выявлении MSI-H показано направление к генетику, генетическое тестирование.

\section{2. Физикальное обследование}

Рекомендуется тщательный физикальный осмотр, включающий пальцевое ректальное исследование, оценку нутритивного статуса.

\section{3. Лабораторная диагностика}

Рекомендуется выполнять развернутые клинический и биохимический анализы крови, онкомаркер РЭА, исследование свёртывающей системы крови, анализ мочи. Исследование свертывающей системы крови и общий анализ мочи обязательно выполняется перед хирургическим лечением, у остальных больных - при наличии клинических показаний. Выполнение анализов крови на маркер РЭА показано всем больным РПК. Конкретный набор параметров биохимического анализа крови и коагулограммы должен определять лечащий врач индивидуально, с учётом особенностей конкретного пациента.

\section{4. Инструментальная диагностика}

Колоноскопия с биопсией - наиболее информативный метод исследования при РПК, позволяющий непосредственно визуализировать опухоль, определить её размеры, локализацию и макроскопический тип, оценить угрозу осложнений (кровотечение, перфорация), а также получить материал для морфологического исследования. Для получения достаточного количества материала требуется выполнить несколько (3-5) биопсий стандартными эндоскопическими щипцами. План лечения не следует составлять до получения данных биопсии. При подслизистом инфильтративном росте опухоли возможен ложноотрицательный результат, что требует повторной глубокой биопсии. Чувствительность и специфичность метода возрастает при использовании современных технологий эндоскопической визуализации (увеличительной эндоскопии, узкоспектральной эндоскопии, хромоэндоскопии, флуоресцентной диагностики). Если тотальная колоноскопия не была выполнена на дооперационном этапе, ее необходимо провести в течение 3-6 месяцев после хирургического лечения. Необходимость выполнения тотальной колоноскопии диктуется высоким риском выявления синхронных полипов и рака вышележащих отделов толстой кишки.

МРТ малого таза перед планированием ХЛТ и хирургическим лечением позволяет определить локализацию, протяженность, глубину инвазии опухоли, оценить состояние регионарных лимфатических узлов. В протоколе заключения МРТ малого таза при РПК рекомендуется указывать следующую информацию: 
-

- глубину инвазии в стенку прямой кишки;

- минимальное расстояние от края опухоли до мезоректальной фасции;

- количество и размеры лимфатических узлов параректальной клетчатки;

- наличие МР-признаков их злокачественного поражения;

- наличие вовлечения мезоректальной фасции потенциально поражёнными лимфатическими узлами;

- наличие венозной инвазии;

- количество и размеры экстрафасциальных лимфатических узлов;

- наличие МР-признаков их злокачественного поражения;

- для рака нижнеампулярного отдела прямой кишки - наличие инвазии внутреннего сфинктера / межсфинктерного пространства/наружного сфинктера / мышц, поднимающих задний проход.

Современные режимы МРТ с использованием диффузно-взвешенных изображений могут повысить информативность проводимого исследования. В/в контрастирование не повышает информативность оценки распространённости опухоли. Окончательное принятие решение о тактике лечения больных РПк возможно только по результатам МРТ-исследования.

2.4.1. Ирригоскопия или КТ-колонография при невозможности выполнения тотальной колоноскопии. В 4-5\% случаев встречаются синхронные образования, которые могут быть пропущены при пальпаторной ревизии на операции. Поэтому полное обследование толстой кишки рекомендуется выполнять всем пациентам до хирургического лечения, при технической невозможности не позднее 3-6 мес. после хирургического лечения. КТ-колонография имеет бо́льшую по сравнению с ирригоскопией чувствительность в выявлении полипов, особенно в проксимальных отделах толстой кишки.

2.4.2. УЗИ органов брюшной полости и забрюшинного пространства либо КТ органов брюшной полости с в/в контрастированием. КТ органов брюшной полости и грудной клетки является стандартом уточняющей диагностики при РПК в большинстве развитых стран. Выполнение только УЗИ допустимо только при технической невозможности проведения КТ.

2.4.3. Рентгенография грудной клетки либо КТ органов грудной клетки. КТ органов грудной клетки является стандартом уточняющей диагностики при РПК в большинстве развитых стран для исключения метастазов в легких, лимфоузлах средостения. На практике данное исследование может быть отчасти заменено у пациентов с небольшой местной распространенностью опухолевого процесса. Резектабельность метастазов в лёгких необходимо оценивать по данным КТ грудной клетки. КТ позволяет у 20-25\% пациентов выявить не определяемые по данным рентгенографии метастазы и сократить количество эксплоративных операций и операций в объёме R2. Не допускается планирование резекции метастазов в лёгких на основании данных только рентгенографии органов грудной клетки. 
2.4.4. Рекомендуется выполнение ЭКГ перед планированием любого вида лечения. У пациентов, получающих противоопухолевую лекарственную терапию, ЭКГ выполняется по клиническим показаниям.

2.4.5. УЗ колоноскопия - при планировании местного иссечения Т1sm1 и ворсинчатых опухолей прямой кишки.

2.4.6. Рекомендуется оценивать резектабельность метастазов в печени по данным МРТ брюшной полости с в/в контрастированием или КТ брюшной полости с в/в контрастированием. Рекомендуется выполнять МРТ органов брюшной полости с в/в контрастированием при планировании резекции печени в случаях, когда КТ с в/в контрастированием не позволяет в полной мере высказаться о распространенности процесса в печени. Для оценки резектабельности метастазов колоректального рака в печени предпочтительно использование МРТ органов брюшной полости с в/в контрастированием. Пациентам с противопоказанием к использованию в/в контрастирования возможно выполнение МРТ с режимом DWI. MPT позволяет у 10-20\% пациентов выявить не определяемые по данным УЗИ метастазы и сократить количество эксплоративных операций и операций в объёме R2. Пациентам с противопоказанием к выполнению МРТ рекомендуется выполнение КТ с в/в контрастированием или ПЭТ/КТ с в/в контрастированием. МРТ обладает наиболее высокой чувствительностью по сравнению с другими диагностическими методами, в особенности в отношении метастазов размерами менее 1 см. Не допускается планирование резекции метастазов на основании данных только УЗИ печени или КТ без в/в контрастирования.

2.4.7. Остеосцинтиграфия - при подозрении на метастатическое поражение костей скелета.

2.4.8. Биопсия под контролем УзИ/КТ - при подозрении на метастазы по данным КТ или МРТ в случаях, когда их подтверждение принципиально меняет тактику лечения.

2.4.9. ПЭТ/КТ - при подозрении на метастазы по данным КТ или МРТ в случаях, когда их подтверждение принципиально меняет тактику лечения. Метаанализ рандомизированных исследований по определению необходимости выполнения ПЭТ/КТ для исключения экстрапеченочных метастазов при решении вопроса о метастазэктомии в печени показал, что данный метод обследования меняет тактику лечения лишь у $8 \%$ пациентов и не влияет на общую выживаемость.

2.4.10. Лапароскопия при резектабельных стадиях болезни - при подозрении на диссеминацию опухоли по брюшине.

2.4.11. МРТ или КТ головного мозга с в/в контрастированием - при подозрении на метастатическое поражение головного мозга.

2.4.12. При подготовке к хирургическому лечению с целью оценки функционального статуса по показаниям рекомендуется проводить дополнительное об- 
следование: ЭхоКГ, холтеровское мониторирование сердечной деятельности, исследование ФВД, УЗДГ сосудов шеи и нижних конечностей, консультации кардиолога, эндокринолога, невропатолога и т. п.

\section{5. Иная диагностика}

2.5.1. Анализ биоптата опухоли на мутацию в генах семейства RAS (экзоны 2-4 генов KRAS и NRAS), гена BRAF и на MSI, если диагностированы отдаленные метастазы, что может повлиять на выбор таргетного агента в лечении метастатического процесса. При отсутствии мутации в генах семейства RAS, BRAF возможно дополнительное определение экспрессии или амплификации HER2.

2.5.2. Генетическое тестирование рекомендуется в следующих случаях:

2.5.2.1. Подозрение на синдром Линча. Выполняется тестирование на мутации в генах MLH1, MSH2, MSH6, PMS2:

- при соответствии пациента критериям Amsterdam II (приложение A);

- при наличии у пациента родственника первой или второй линии с установленным диагнозом синдрома Линча;

- при развитии у пациентки рака эндометрия в возрасте до 50 лет.

2.5.2.2. Подозрение на синдром Линча у пациентов, не отвечающих критериям Amsterdam. При соответствии критериям Bethesda (приложение Б) выполняется тестирование опухоли на MSI, при выявлении MSI-H - тестирование на герминальные мутации в генах MLH1, MSH2, MSH6, PMS2.

2.5.2.3. Подозрение на семейный аденоматоз - тестирование на мутацию гена АРС:

- при наличии у пациента более 100 полипов кишечника;

- при наличии у пациента родственника первой линии с установленным диагнозом семейного аденоматоза толстой кишки (при наличии родственника с выявленной наследственной мутацией гена APC).

2.5.2.4. Подозрение на наличие аттенуированной формы семейного аденоматоза (от 20 до 100 полипов) - тестирование на мутацию APC. MutYH-ассоциированный полипоз - необходимо тестировние на мутацию гена MutYH-пациенты, у которых выявлено более 20 полипов толстой кишки, но с отрицательным анализом на мутацию APC: пациенты, у которых в семье прослеживается рецессивное наследование семейного аденоматоза; пациенты, у которых полипы выявляются в более позднем возрасте (34-44 лет).

За исключением MutYH-ассоциированного полипоза и синдрома Блума все наследственные синдромы, связанные с развитием колоректального рака, носят аутосомно-доминантный характер. При наличии яркого семейного анамнеза злокачественных заболеваний пациентам с исключённым семейным аденоматозным полипозом и синдромом Линча показана консультация генетика для потенциального выявления более редких заболеваний: синдро- 
мов Пейтца-Егерса, Ли-Фраумени, Блума, Коудена, ювенильного полипоза, олигодонтии и колоректального рака.

2.5.3. Гистологическое исследование хирургически удаленного опухолевого препарата. В морфологическом заключении рекомендуется отразить следующие параметры:

- расстояние до проксимального и дистального краёв резекции;

- размеры опухоли;

- гистологический тип опухоли (согласно Классификации ВОЗ);

- степень злокачественности опухоли (низкая, высокая);

- $\mathrm{pT}$;

- $\quad$ pN (с указанием общего числа исследованных и поражённых лимфоузлов);

- в случае выявления при рутинном окрашивании или иммуногистохимически в лимфоузле не более 200 изолированных опухолевых клеток, считать лимфоузел метастаз-негативным (N0);

- наличие в периколярной жировой ткани изолированных опухолевых депозитов без предсуществующих структур лимфатического узла (иначе следует относить к метастазу), сосудистых структур (иначе следует относить к сосудистой инвазии) или нервов (иначе следует относить к периневральной инвазии);

- наличие поражения проксимального края резекции (отрицательный результат также должен быть констатирован);

- наличие поражения дистального края резекции (отрицательный результат также должен быть констатирован);

- макроскопически оценить объем выполненной хирургом диссекции регионарной клетчатки в пределах мезоректальной фасции (согласно методике P. Quirke): TME-G1 / G2 / G3;

- при микроскопическом исследовании указать расстояние в миллиметрах от ближайшего фокуса опухоли (первичный очаг или депозит или метастаз) до маркированного красителем циркулярного края резекции (согласно методике P. Quirke);

- наличие интрамуральной и экстрамуральной сосудистой инвазии (отрицательный результат также должен быть констатирован);

- наличие периневральной инвазии (отрицательный результат также должен быть констатирован);

- гистологическая градация инвазивного фронта опухоли (tumor-budding) по 3-ступенчатой схеме, а также характера роста аденокарциномы/рака (инфильтративный, экспансивный);

- гистологические признаки, значимо ассоциированные с MSI-H (зубчатая, перстневидноклеточная, муцинозная и медуллярная аденокарцинома, интра-и перитуморальная лимфоидная инфильтрация, правосторонняя локализация опухоли);

- степень регрессии опухоли (TRG1-TRG5) по шкале Mandard (при наличии предшествующего комбинированного лечения); 
- поражение апикального лимфатического узла при его наличии в препарате (отрицательный результат также должен быть констатирован).

2.5.4. Рекомендуется в морфологическом заключении после трансанального эндоскопического удаления опухоли прямой кишки указывать следующие параметры:

- расстояние до ближайшего края резекции (латерального и вертикального);

- размеры опухоли;

- гистологический тип опухоли (согласно Классификации ВОЗ);

- степень злокачественности опухоли (низкая, высокая);

- наличие фрагментации препарата;

- $\quad$ рт с указанием глубины подслизистой инвазии опухоли;

- наличие лимфоваскулярной инвазии (отрицательный результат тоже должен быть констатирован);

- наличие периневральной инвазии (отрицательный результат тоже должен быть констатирован);

- гистологическая градация инвазивного фронта опухоли (tumor-budding) по 3-ступенчатой схеме, а также характера роста аденокарциномы/рака (инфильтративный, экспансивный).

\section{3. ЛЕЧЕНИЕ}

\section{1. Общие принципы}

3.1.1. Хирургическое вмешательство является основным методом радикального лечения больных РПК, за исключением плоскоклеточного РПК. По показаниям дополнительно проводится адъювантная/неоадъювантная XТ, ЛТ, ХЛТ. Лечение плоскоклеточного РПК проводится в соответствии с принципами, описанными в клинических рекомендациях по лечению плоскоклеточного рака анального канала. Данный вариант РПК - редкое заболевание. Несмотря на локализацию вне анального канала, эта опухоль имеет высокую чувствительность к ХЛТ, и локализованные формы заболевания могут быть излечены без применения хирургического этапа лечения.

3.1.2. У всех пациентов с полипами толстой кишки без признаков малигнизации при технической возможности должно быть выполнено их эндоскопическое удаление. Перед удалением полипов размерами 1 см и более должна быть выполнена биопсия и исключена малигнизация. Биопсия должна браться как с поверхности, так и из зоны ножки полипа. Даже в полипах размерами менее 5 мм у 1,5\%-7,7\% пациентов могут присутствовать фокусы злокачественного роста. Более высока вероятность малигнизации для проксимально расположенных полипов, а также у пациентов с множественными полипами толстой кишки. Единичные дистально расположенные полипы размерами менее 5 мм имеют минимальный риск злокачественной трансформации. Риск озлокаче- 
ствления пропорционален размеру полипа и составляет 3-15,9\% для полипов размерами 5-20 мм и 7-19,3\% - для полипов размерами более 20 мм. После полипэктомии всем пациентам должно быть рекомендовано наблюдение. Периодичность наблюдения зависит от числа и размера полипов, наличия установленных наследственных синдромов. При одновременном наличии РПК и полипов толстой кишки удаление полипов предпочтительно выполнять до резекции кишки, если они локализуются вне зоны планируемой резекции (учитывая вероятность неявки пациента для выполнения полипэктомии после операции). При невозможности санации полипов до резекции кишки должны быть задокументированы рекомендации по их удалению в течение 6 месяцев после операции.

3.1.3. Рекомендуется проводить предоперационную лучевую или химиолучевую терапию всем больным со следующими стадиями РПК: сТлюбое N1-2М0 рак нижне-и среднеампулярного отделов прямой кишки, сT2-4N0M0 рак нижнеампулярного отдела прямой кишки, сT3с - 4N0MO рак среднеампулярного отдела прямой кишки, сT4b - N0-2M0 рак верхнеампулярного отдела прямой кишки. Для пациентов с другими стадиями РПК - см. разделы рекомендаций по хирургическому лечению РПК и лечению метастатического РПК. В условиях НМИЦ и федеральных центров по решению мультидисциплинарной команды возможно проведение хирургического лечения без предоперационной лучевой/химиолучевой терапии всем больным раком верхнеампулярного отдела прямой кишки и больным раком среднеампулярного отдела прямой кишки ст1-3bN1M0.

3.1.4. Больным РПК с резектабельными отдалёнными метастазами и благоприятным прогнозом рекомендуется рассматривать проведение предоперационной Лт по показаниям, аналогичным таковым для неметастатического РПК (ст сT2-4N0M1 рак нижнеампулярного отдела прямой кишки, сT3с-4N0M1 рак среднеампулярного отдела прямой кишки, ст пюбое 2 2M1, сT4b-N0-2M1 рак верхнеампулярного отдела прямой кишки). В остальных ситуациях решение о проведении ЛТ больным метастатическим РПК принимается индивидуально, с учётом прогноза заболевания, наличия симптомов со стороны первичной опухоли.

3.1.5. Рекомендуется использование следующих режимов лучевой и химиолучевой терапии: 1) курс дистанционной конформной лТ. РОД на первичную опухоль и зону регионарного метастазирования РОД 5 Гр, 5 фракций до СОД 25 Гр в течение 5 последовательных дней или 2) курс дистанционной конформной ЛТ в комбинации с ХТ фторпиримидинами. ЛТ РОД 1,8-2 Гр, СОД 44 Гр на зоны регионарного метастазирования. СОД 50-54 Гр на первичную опухоль. Лечение ежедневно, 5 раз в неделю, фотонами 6-18 МэВ.

Объём облучения на зону регионарного метастазирования должен включать пресакральные, параректальные, обтураторные, внутренние подвздошные, 
нижние брыжеечные лимфоузлы. Начинается дистанционная ЛТ с объемного 3D-планирования и выполняется по технологии конформной лт. Предлучевая топометрическая подготовка включает в себя выполнение КТ и МРТ исследований, на основании чего формируется план облучения. Точность воспроизведения условий лТ контролируется с помощью системы портальной визуализации. Возможно проведение лТ на протонных ускорителях энергией 70-250 МэВ с использованием протонных комплексов.

Возможные варианты ХТ в режимах ХЛТ представлены в табл. 2.

Таблица 2. Режимы фторпиримидинов, применяемые в одновременной химиолучевой терапии рака прямой кишки

\begin{tabular}{|c|c|c|c|c|c|c|}
\hline $\begin{array}{l}\text { Схема } \\
\text { химио- } \\
\text { терапии }\end{array}$ & Препарат & Доза & $\begin{array}{l}\text { Путь } \\
\text { введения }\end{array}$ & Дни приема & $\begin{array}{l}\text { Длитель- } \\
\text { ность } \\
\text { цикла, дни }\end{array}$ & $\begin{array}{l}\text { Количество } \\
\text { циклов }\end{array}$ \\
\hline 1 & \multicolumn{3}{|c|}{$\begin{array}{l}\text { Непрерывная инфузия 5-фторурацила } \\
225 \text { мг/м² в/в непрерывно }\end{array}$} & \multirow{2}{*}{$\begin{array}{l}\text { В дни Лт } \\
\text { в зависимости } \\
\text { от переноси- } \\
\text { мости }\end{array}$} & \multirow[t]{2}{*}{$\begin{array}{l}\text { На протяже- } \\
\text { нии всей Лт }\end{array}$} & \multirow[t]{2}{*}{$\begin{array}{l}\text { На протяже- } \\
\text { нии всей ЛТ }\end{array}$} \\
\hline 2 & Капецитабин & $\begin{array}{l}825 \text { мг/м }{ }^{2} \\
2 \text { раза в сутки }\end{array}$ & Внутрь & & & \\
\hline \multirow[t]{2}{*}{3} & $\begin{array}{l}\text { Болюсная } \\
\text { инфузия } \\
\text { 5-фторурацила }\end{array}$ & $400 \mathrm{Mr} / \mathrm{M}^{2}$ & $\begin{array}{l}\text { Внутри- } \\
\text { венно }\end{array}$ & $\begin{array}{l}\text { Дни 1-4, неде- } \\
\text { ли } 1,5\end{array}$ & 1-4 день & 2 цикла \\
\hline & $\begin{array}{l}\text { Болюсная } \\
\text { инфузия } \\
\text { Лейковорина }\end{array}$ & $20 \mathrm{Mr} / \mathrm{M}^{2}$ & $\begin{array}{l}\text { Внутри- } \\
\text { венно }\end{array}$ & $\begin{array}{l}\text { Дни 1-4, неде- } \\
\text { ли } 1,5\end{array}$ & 1-4 день & 2 цикла \\
\hline
\end{tabular}

3.1.6. В сравнении с послеоперационной ХЛТ эффективность предоперационной ХЛТ выше, а токсичность меньше, поэтому применение послеоперационной ЛТ (54 Гр по 2 Гр за фракцию на фоне терапии фторпиримидинами (табл. 2)) допустимо только у пациентов, которым по каким-либо причинам такое лечение не было выполнено на дооперационном этапе или при выявлении положительного циркулярного края резекции после хирургического лечения. Больным раком нижнеампулярного отдела прямой кишки и больным с вовлечением мезоректальной фасции рекомендуется проведение пролонгированных курсов ХЛТ с СОД не менее 50 Гр, если регрессия опухоли может повлиять на выбор объёма операции. Альтернативные режимы лт с меньшей вероятностью обеспечивают регрессию и повышение резектабельности опухоли.

3.1.7. Рекомендуется после пролонгированного курса ХЛТ проводить хирургическое лечение не ранее 7 и не позднее 12 нед.

Ожидание более 8 нед. не увеличивает вероятность достижения полного лечебного патоморфоза и не влияет на выживаемость пациентов. При отсутствии осложнений 3-4 степени возможно дополнительное проведение XТ по схеме mFOLFOX6 или XELOX во время интервала до хирургического лечения. 
3.1.8. Рекомендуется после курса ЛТ РОД 5 Гр, СОД 25 Гр проводить хирургическое лечение через 1-10 дней или через 6-10 нед.

Онкологические результаты сопоставимы для различных интервалов после лт. При использовании длительного интервала может снижаться риск послеоперационных осложнений, однако более выражены лучевые реакции со стороны вошедших в зону лечения тканей.

3.1.9. У значительного числа больных возможно достичь стойкой полной регрессии опухоли. Условиями для проведения данной тактики лечения являются:

- полное информированное согласие пациента суказанием возможных осложнений ХЛТ и альтернативных вариантов лечения;

- возможность явки пациента на контрольные обследования не реже 4 раз в год в течение не менее чем 3 лет после завершения ХЛТ. Письменное согласие пациента на проведение контрольных обследований с необходимой регулярностью.

3.1.10. При исходной возможности выполнения операция в объёме передней резекции прямой кишки с парциальной мезоректумэктомией, связанной с меньшим риском снижения качества жизни, использование тактики «наблюдения и ожидания» не оправдано и может рассматриваться только у пациентов с объективными противопоказаниями или крайне высоким риском проведения радикального хирургического лечения.

3.1.11. Возможно проведение тотальной неоадъювантной ХТ или периоперационной ХТ больным РПК сT4NлюбаяМ0 и сТлюбаяN1-2М0. Под тотальной неоадъювантной XT подразумевается проведение курса XT на дооперационном этапе, до или после лучевой/химиолучевой терапии. Количество курсов XТ выбирается согласно принципам, описанным в разделе по адъювантной XТ. Стадирование выполняется на основании данных МРТ. Периоперационная XT подразумевает проведение части курсов XТ на дооперационном, а части - на послеоперационном этапе. Данный подход продемонстрировал безопасность в рамках клинических исследований, однако его влияние на отдалённые результаты до конца не изучено. Потенциальные преимущества включают более высокую частоту проведения полного курса XТ и влияние на степень регрессии опухоли. Потенциальные недостатки - избыточное назначение ХT пациентам с завышением стадии по данным МРТ.

При наличии показаний к проведению Лт возможно применение различных сочетаний предоперационнойХТ и ЛТ: 1) короткий курс ЛТ (5 × 5 Гр) с последующими 18 неделями XT режимом FOLFOX или XELOX; 2) 18 недель предоперационной ХT режимом FOLFOX или XELOX и пролонгированный курс ХЛТ (СОД не менее 50 Гр на фоне фторпиримидина). Последовательность ХЛТ $\rightarrow$ ХТ у пациентов с дистальными опухолями приводит к большей вероятности сохранения органа по сравнению с обратной последовательностью. 
3.1.12. При исходно нерезектабельном РПК (T4bN0-2M0) рекомендуется проведение мелкофракционной дистанционной конформной ЛТ в комбинации с XТ фторпиримидинами и последующей повторной оценкой резектабельности в условиях специализированных учреждений. Вколоченные неподвижные опухоли, врастающие в окружающие органы и ткани, когда исходная возможность выполнения резекции в объёме R0 сомнительна: Лт СОД не менее 54 Гр на первичную опухоль. При технической доступности линейных ускорителей в режиме многопольного облучения с защитой окружающих тканей IMRT, VMAT СОД может быть увеличена до 58 Гр. При отсутствии осложнений 3-4 степени возможно дополнительное проведение XT по схеме XELOX или FOLFOX во время интервала до хирургического лечения. Через 10-12 нед. после окончания курса ХЛТ повторно выполняется МРТ малого таза, оценивается операбельность опухоли. Если резектабельность опухоли не достигнута, допустимо назначение XT в режиме XELOX или FOLFOX 4-6 циклов с последующей MPT малого таза для оценки эффекта. В случае осложненного течения со стороны первичной опухоли (кровотечение, непроходимость, наличие связанных с опухолью свищей) перед ХЛт необходимо рассмотреть вопрос о колостомии / стентировании прямой кишки как альтернативы паллиативной резекции прямой кишки. Дальнейшие варианты лечения включают попытку радикального хирургического лечения, паллиативное хирургическое лечение, паллиативную лекарственную терапию. У пациентов старческого возраста с тяжёлыми сопутствующими заболеваниями допустимо проведение дистанционной конформной ЛТ РОД 5 Гр, СОД 25 Гр в течение 5 последовательных дней с пролонгированным интервалом (6-10 нед.) до оценки эффекта и решения вопроса о проведении хирургического вмешательства. С целью увеличения шанса резектабельности после ХЛт возможно проведение системной ХТ.

\section{2. Хирургическое лечение}

3.2.1. Перед операцией у всех больных РПК необходимо получить информированное согласие на проведение хирургического вмешательства и формирование колостомы (даже если это не предполагается в плане операции).

3.2.2. При технической доступности и наличии квалифицированной бригады хирургов рекомендуется проводить хирургическое лечение РПК лапароскопическим доступом. Лапароскопические резекции прямой кишки имеют ряд преимуществ, включая раннюю реабилитацию пациентов, снижение частоты развития и выраженности спаечного процесса, меньшее использование опиоидных анальгетиков, снижение сроков госпитализации, меньший риск развития послеоперационных грыж и лучший косметический результат операции. По своей онкологической эффективности лапароскопические операции по поводу РПК не уступают открытым вмешательствам, однако, требуют соответствующей подготовки хирургической бригады. 
3.2.3. Рекомендуется при наличии противопоказаний к формированию первичного анастомоза выполнять обструктивную резекцию с формированием концевой колостомы (операция Гартмана).

3.2.4. Рекомендуется выполнять следующие стандартные объёмы оперативных вмешательств у больных РПК: передняя резекция прямой кишки, низкая передняя резекция прямой кишки, брюшно-анальная резекция прямой кишки, операция Гартмана, брюшно-промежностная экстирпация прямой кишки. Мобилизация прямой кишки должна выполняться только острым путём (в том числе с использованием электрохирургических и ультразвуковых инструментов высокой энергии) с соблюдением принципов тотальной или частичной мезоректумэктомии (необходимо удаление мезоректума не менее 5 см дистальнее опухоли) с сохранением тазовых вегетативных нервов. Формирование колоректального анастомоза предпочтительно делать с использованием циркулярного сшивающего аппарата, для пересечения кишки - использовать линейно-режущие сшивающие аппараты. При распространении опухоли за пределы мезоректальной фасции показано экстрафасциальное удаление прямой кишки. При выполнении мультивисцеральных резекций для рассечения тканей предпочтительно использовать электрохирургические и ультразвуковые инструменты с целью уменьшения кровопотери. Дистальная граница резекции должна составлять не менее 2 см по стенке кишки и не менее 5 см по мезоректальной клетчатке из-за риска ретроградного лимфогенного метастазирования. Нижняя брыжеечная артерия должна быть лигирована непосредственно у места отхождения от аорты либо непосредственно ниже уровня отхождения левой ободочной артерии, перевязка нижней брыжеечной вены - ниже тела поджелудочной железы, что позволяет мобилизовать левые отделы ободочной кишки (при необходимости с полной мобилизацией селезеночного изгиба) для формирования колоректального анастомоза без натяжения. Допустима перевязка нижней брыжеечной вены на том же уровне, что и нижней брыжеечной артерии. При этом следует при технической возможности сохранять преаортальное и нижнее брыжеечное вегетативные нервные сплетения. Мобилизацию прямой кишки следует производить в межфасциальном пространстве с сохранением (при отсутствии опухолевого поражения) правого и левого подчревных нервов, тазовых сплетений и внутренностных нервов. Рутинное выполнение расширенной аорто-подвздошно-тазовой лимфодиссекции не рекомендуется. При выполнении тотальной мезоректумэктомии (локализация опухоли ниже 10 см от края ануса) и формировании низкого колоректального анастомоза рекомендуется формировать превентивную коло- или илеостому. После тотальной мезоректумэктомии операция может завершаться формированием тазового толстокишечного резервуара или анастомоза «бок-в-конец» для улучшения функциональных результатов лечения.

3.2.5. Выполнение экстралеваторной экстирпации прямой кишки показано пациентам с подтверждённым МРТ врастанием опухоли в мышцы тазового дна. 
3.2.6. Рекомендуется у пациентов с кишечной непроходимостью, а также со свищами, вызванными РПК, ограничивать хирургическое лечение формированием двуствольной трансверзо - или сигмостомы с целью проведения последующего комбинированного лечения. Рекомендуется формировать трансверзостому, если во время основной операции планируется формирование анастомоза. Рекомендуется формировать сигмостому, если наиболее вероятный объём операции - брюшно-промежностная экстирпация прямой кишки.

3.2.7. У пациентов с не купируемым консервативно клинически значимым кровотечением и/или перфорацией с развитием перитонита, вызванными РПК, показано на первом этапе выполнение оперативного вмешательства с соблюдением принципов тотальной мезоректумэктомии. При других осложнениях опухолевого процесса предпочтение следует отдавать формированию временной или постоянной кишечной стомы. Выполнение на первом этапе хирургических вмешательств с удалением первичной опухоли возможно только в отдельных случаях по решению онкологического консилиума с участием хирурга-онколога, лучевого терапевта, химиотерапевта и документированным обоснованием невозможности проведения предоперационного лечения. В отдельных случаях, при условии наличия в клинике должного опыта и оборудования, разрешение непроходимости возможно путём стентирования с последующей подготовкой пациента к плановому хирургическому или комбинированному лечению.

3.2.8. При раннем РПК 0-І стадии (Tis-T1sm1-sm2N0M0) рекомендуется выполнять хирургическое лечение методом трансанального полнослойного эндоскопического удаления опухоли или эндоскопической подслизистой диссекции. Особенность - благоприятный прогноз (5-летняя выживаемость более $90 \%$ ) и возможность применения органосохраняющих и функционально-щадящих способов лечения с высокой эффективностью. При отсутствии в клинике оборудования для выполнения трансанального эндоскопического удаления опухоли или опыта выполнения эндоскопической подслизистой диссекции показано направление пациента в специализированный центр, где возможно проведение необходимого лечения.

Показания к проведению органосохранного лечения:

- размеры опухоли<3 см,

- поражение не более $30 \%$ окружности кишки,

- подвижность образования,

- умеренно-или высокодифференцированная аденокарцинома,

- перстневидноклеточный рак,

- степень почкования опухоли (tumor budding) 2-3

3.2.9. Трансанальная эндоскопическая резекция (TEO, TEM, TAMIS) должна сопровождаться полнослойным иссечением стенки кишки с прилежащей мезоректальной клетчаткой. 
При выявлении после морфологического исследования удалённой трансанально опухоли факторов негативного прогноза выполняется стандартная операция с тотальной мезоректумэктомией (ТМЭ). Факторы негативного прогноза:

- стадия $\geq$ pT1sm3

- поражение краёв резекции

- сосудистая или периневральная инвазия

- низкодифференцированная или слизистая аденокарцинома.

Адъювантная терапия не проводится.

При выявлении после операции:

- поражения опухолью циркулярного края резекции,

- $\mathrm{pT}_{\text {любое }} \mathrm{N2}$

- $\quad$ рT3-4N $\mathrm{N}_{\text {любе }}$ для рака нижнеампулярного отдела прямой кишки

- $\quad$ рТ3с-4N

назначается послеоперационная ХЛТ. При условии выполнения операции в референсном центре (только НМИЦ и федеральные учреждения) и подтверждении в морфологическом заключении удовлетворительного/высокого качества мезоректумэктомии возможно отказаться от проведения послеоперационной ХлТ. В случае отсутствия предоперационного лечения при II-III стадии РПК проведение адъювантной ХТ определяется правилами ее назначения, как при раке ободочной кишки.

\section{3. Лечение пациентов с резектабельными метастазами в печени}

3.3.1. Рекомендуется всех больных с изолированным метастатическим поражением печени / лёгких на долечебном этапе обсуждать совместно с абдоминальными (имеющими опыт выполнения резекций печени)/торакальными хирургамионкологами.

3.3.2. При генерализованном РПК с резектабельными/потенциально резектабельными синхронными метастазами в печени и/или лёгких рекомендуется выполнять хирургическое вмешательство в объеме R0, как только метастазы будут признаны резектабельными. Тактика лечения зависит от исходной резектабельности метастатических очагов. Наилучших результатов возможно добиться при достижении края резекции не менее 1 мм. При исходной возможности выполнения R0-резекции метастазов РПК в печени или лёгких, а также при переходе метастатического поражения этих органов в резектабельное состояние в процессе XT проведение хирургического лечения в объёме R0 может обеспечить 5-летнюю выживаемость у 30-50\% пациентов. Пациентам, которые ранее получали XT, хирургическое вмешательство в объеме R0 необходимо выполнять, как только метастазы станут резектабельными. Пролонгация XT может приводить к повышению частоты токсических поражений печени, 
а также к «исчезновению» части метастазов, что затрудняет их идентификацию хирургом во время резекции. При наличии симптомной первичной опухоли (угрозе кишечной непроходимости / кровотечения) на первом этапе проводится хирургическое удаление первичной опухоли с лимфодиссекцией. РЧА метастазов в печени или стереотаксическое лучевое воздействие может применяться как дополнение к резекции для достижения радикальности вмешательства, так и самостоятельно при невозможности хирургического лечения. Добавление МКА к XТ не показано при резектабельных метастазах, так как может ухудшать отдаленные результаты.

3.3.3. При генерализованном РПК с нерезектабельными синхронными метастазами рекомендуется проведение максимально эффективной ХT, задачей которой является достижение объективного эффекта и перевод нерезектабельных метастазов в резектабельные. Показано применение двойных комбинаций (FOLFOX, XELOX или FOLFIRI, XELIRI). В случае отсутствия мутации RAS возможно добавление к режимам XT FOLFIRI или FOLFOX (но не XELOX/XELIRI или FLOX) анти-EGFR MKA, что позволяет увеличить частоту выполнения R0-резекций печени. Альтернативой является добавление бевацизумаба к любому двойному режиму XT (вне зависимости от мутации RAS), что повышает частоту выраженного лекарственного патоморфоза по сравнению с ХТ в самостоятельном варианте. Другой возможной опцией повышения резектабельности является применение «тройной» комбинации FOLFOXIRI, к которой возможно добавление МКА, однако более высокая токсичность режима требует осторожности при его назначении. В/а ХТ остается экспериментальным методом и не рекомендуется к рутинному применению в первой линии терапии. Различные методы эмболизации печеночной артерии, в/а ХТ могут применяться у отдельных пациентов с изолированным или преобладающим метастатическим поражением печени при исчерпанности возможностей системной терапии. Больные, у которых ответ на лечение недостаточен для перевода опухоли в резектабельное состояние, подлежат паллиативному лекарственному лечению. Вопрос об удалении первичной опухоли решается индивидуально с учётом риска развития связанных с ней осложнений. При условии хорошего ответа на проводимую терапию проводится повторная оценка резектабельности метастатических очагов. При микросателлитной нестабильностью высокого уровня возможно назначение в первой линии иммунотерапии: комбинации ниволумаба и ипилимумаба (особенно у пациентов в мутацией в гене RAS), или пембролизумаба в монорежиме до прогрессирования или непереносимой токсичности.

3.3.4. При метахронных резектабельных метастазах РПК в печени или лёгких рекомендуется проведение хирургического лечения с послеоперационной XТ двойными (FOLFOX, XELOX) комбинациями препаратов. При исходной возможности выполнения R0-резекции метастазов РПК в печени или лёгких, а также при переходе метастатического поражения этих органов в резектабельное состояние в процессе XT проведение хирургического лечения в объёме RO 
может обеспечить 5-летнюю выживаемость у 30-50\% пациентов. Альтернативой данному подходу является проведение периоперационной (около 3 мес. терапии FOLFOX или XELOX до резекции печени и столько же - после нее) XТ. При распространённом опухолевом процессе в печени, делающем невозможным / сомнительным выполнение R0-резекции, показано проведение максимально активной терапии для перевода этих метастазов в резектабельные. Обычно применяют двойные комбинации химиопрепаратов (FOLFOX, XELOX, FOLFIRI, XELIRI, FOLFOXIRI) с возможным добавлением (принципы лечения указаны выше) MKA.

3.3.5. При исходно резектабельных метастатических очагах после успешного проведения R0- или R1-резекции рекомендуется проведение адъювантной XT. Альтернативой немедленному хирургическому лечению является проведение периоперационной системной XT (FOLFOX, XELOX). После 4-6 циклов выполняется одновременное или последовательное удаление метастазов и первичной опухоли, а после операции продолжается проводимая ранее ХТ до суммарной продолжительности 6 мес. Добавление МКА к ХТ при резектабельных метастазах в печень не показано, так как может ухудшать отдаленные результаты.

3.3.6. При потенциально резектабельных синхронных и метахронных метастатических очагах рекомендуется проведение максимально эффективной XT, задачи которой - достижение объективного эффекта и перевод нерезектабельных метастазов в резектабельные (FOLFOX, XELOX или FOLFIRI, XELIRI, FOLFOXIRI).

3.3.7. При потенциально резектабельных метастатических очагах в случае отсутствия мутаций в генах семейства RAS и BRAF рекомендуется добавление к режимам XT FOLFIRI или FOLFOX или FOLFOXIRI анти-EGFR MKA (цетуксимаб или панитумумаб) либо бевацизумаба.

3.3.8. При потенциально резектабельных метастатических очагах при наличии мутации RAS рекомендовано добавление бевацизумаба к любому из указанных выше режимов XT. Другой возможной опцией повышения резектабельности является применение «тройной» комбинации FOLFOXIRI, к которой возможно добавление MKA. После 4-6 циклов выполняется повторная оценка резектабельности, при отсутствии прогрессирования одновременное или последовательное удаление метастазов и первичной опухоли. Далее - адъювантная XТ по программе FOLFOX или XELOX до суммарной продолжительности 6 мес. (с учетом предоперационной XT). В случае прогрессирования/невозможности удаления метастатических очагов лечение проводится по принципам, указанным в пункте лечения больных с нерезектабельными метастазами.

3.3.9. При потенциально резектабельных метастатических очагах при наличии мутации BRAF рекомендовано назначение режима XT FOLFOXIRI с MKA (бевацизумабом). В случае назначения таргетных препаратов после перевода метастазов 
в операбельное состояние и выполнения R0-резекции метастатических очагов проводится XT до суммарной продолжительности 6 мес. Анти-EGFR антитела, бевацизумаб и иринотекан следует в послеоперационном периоде отменить. При R1 / 2-резекции возможно продолжение предоперационной комбинации химиопрепаратов и МКА до суммарной продолжительности 6 мес.

3.3.10. При потенциально резектабельных метастазах с микросателлитной нестабильностью высокого уровня возможно назначение в первой линии комбинации ниволумаба и ипилимумаба (особенно при мутации в генах RAS) или пембролизумаба в монорежиме до прогрессирования или перевода опухоли в операбельное состояние.

3.3.11. При изолированном поражении метастазами брюшины после достижения ремиссии на фоне системной терапии в течение 2-6 мес. рекомендовано рассмотреть возможность удаления метастазов с брюшины.

\section{4. Функционально неоперабельный рак прямой кишки}

3.4.1. При функционально не операбельном РПК (на фоне тяжелой сопутствующей патологии) рекомендуется проведение паллиативного лекарственного лечения либо симптоматической терапии. Возможно стентирование опухоли или формирование разгрузочной кишечной стомы. Риск проведения операции превышает риск, связанный с прогрессированием онкологического заболевания. Решение о наличии противопоказаний к хирургическому лечению может приниматься только на консилиуме с участием хирурга, терапевта, анестезиолога, реаниматолога. Больные данной группы подлежат паллиативному лекарственному лечению либо симптоматической терапии. Возможно стентирование опухоли или формирование разгрузочной кишечной стомы.

\section{5. Рецидивы рака прямой кишки}

3.5.1. При рецидиве РПК рекомендовано проведение предоперационной дистанционной конформной ЛТ РОД 2 Гр, СОД 44 Гр на зону регионарного метастазирования, СОД 54-58 Гр на зону рецидива (в случае, если лТ не проводилась ранее), затем рассмотреть возможность повторного хирургического лечения, при невозможности проведения повторного хирургического лечения рекомендована системная XТ. Даже если пациенту ранее проводилась Лт, необходимо рассмотреть вопрос о возможности дополнительного облучения или локального стереотаксического лучевого воздействия. Операцию выполняют через 10-12 недель после ХЛТ. В случае невозможности проведения ЛТ и выполнения хирургического вмешательства проводят паллиативную ХТ.

3.5.2. При рецидиве РПК, если лТ проводилась ранее, рекомендована консультация лучевого терапевта на предмет возможности проведения повторного курса Лт, проведение повторного курса лт при технической возможности. 
Конкретная схема и дозы повторных курсов лт определяются индивидуально, т. к. возможность проведения повторного лечения зависит от большого количества факторов, включая использованное во время первого курса ЛТ оборудования, особенности выбранного во время первичного лечения объёма облучения и сроков после завершения последнего курса ЛТ. Не всем пациентам возможно проведение повторных курсов Лт. Проведение повторных курсов Лт с СОД менее 30 гр нецелесообразно.

\section{6. Адъювантная химиотерапия}

Рекомендовано назначать адъювантную ХТ в зависимости от проведения предоперационной ХЛТ. В случаях предоперационной ХЛТ назначение адъювантной ХТ основано на результатах патоморфологического исследования. При урT3-4N0 или урT1-4N+проводится адъювантная XT по схеме XELOX или FOLFOX, суммарно до 6 месяцев терапии (включая и длительность предоперационного лечения). При урТ1-2N0 проводится адъювантная ХТ фторпиримидинами в монорежиме до 6 мес. (в случае отсутствия высокого уровня микросателлитной нестабильности в опухоли) или 3 месяца комбинацией XELOX. При урTONO адъювантная XT не проводится или может быть проведена фторпиримидинами в монорежиме. При рT3-4N0 или рT1-3N1-2 в случае, если ЛТ не была проведена до операции, адъювантная ХТ назначается по рекомендациям лечения рака ободочной кишки. В тоже время принимая во внимание результаты исследования IDEA, несмотря на то, что в анализ не включались пациенты, которым проводилась предоперационная ХЛТ, в ситуациях неудовлетворительной переносимости лечения, возможно при урT0-3N0-1 ограничится проведением 3 месяцев химиотерапевтического лечения. Общая продолжительность адъювантной ХТ составляет 6 мес. Обнаруженная микросателлитная нестабильность опухоли при II стадии свидетельствует о хорошем прогнозе, и проведение XT, как правило, не требуется при условии отсутствия рT4N0. Минимальный объем ХТ при III стадии включает в себя фторпиримидины, которые можно применять в различных вариантах: инфузионный (режим De Gramount,) или перорально (капецитабин) (табл. 3). Оптимальный объем адъювантной XТ при III стадии включает комбинацию оксалиплатина с фторпиримидинами в течение 6 мес. Оптимальными являются режимы FOLFOX или XELOX. Комбинация оксалиплатина со струйным фторурацилом (режим FLOX) обладает схожей эффективностью, но сопряжена с высокой токсичностью (является вариантом выбора при развитии кардиотоксичности при применении капецитабина или длительных инфузий фторурацила) (табл. 4). При развитии в процессе ХТ симптомов полинейропатии 2 степени рекомендуется отмена оксалиплатина и продолжение монотерапии фторпиримидинами. В адъювантной терапии колоректального рака не должны применяться иринотекан и таргетные препараты, в частности, бевацизумаб и цетуксимаб, панитумумаб, афлиберцепт, рамуцирумаб, регорафениб. 
Таблица 3. Режимы фторпиримидинов, применяемые в лечении колоректального рака

\begin{tabular}{|c|c|}
\hline Режим & Схема \\
\hline $\begin{array}{l}\text { Модифицированный LV5FU2 } \\
\text { (модифицированный режим De Gramont) }\end{array}$ & $\begin{array}{l}\text { Кальция фолинат } 400 \text { мг/м² в/в в течение } 2 \text { часов с после- } \\
\text { дующим болюсом 5-фторурацила } 400 \text { мг/м² и с последую- } \\
\text { щей 46-часовой инфузией 5-фторурацила } 2400 \text { мг/м² (по } \\
1200 \text { мг/ м² в сут.). } \\
\text { Начало очередного цикла на } 15 \text { день. }\end{array}$ \\
\hline Капецитабин & $\begin{array}{l}\text { 2000-2500 мг/м² в сут. внутрь 1-14 дни. } \\
\text { Начало очередного цикла на } 22 \text { день. }\end{array}$ \\
\hline
\end{tabular}

Таблица 4. Режимы оксалиплатина и фторпиримидинов, применяемые в лечении колоректального рака

\begin{tabular}{|c|c|}
\hline $\begin{array}{l}\text { Модифицированный } \\
\text { FOLFOX } 6\end{array}$ & $\begin{array}{l}\text { Оксалиплатин } 85 \text { мг/м² 2-часовая инфузия в 1-й день, кальция фолинат } \\
400 \text { мг/м² в/в в течение } 2 \text { часов с последующим болюсом 5-фторурацила } \\
400 \text { мг/м² в/в струйно и 46-часовой инфузией 5-фторурацила } 2400 \text { мг/м² (по } \\
1200 \text { мг/м² в сутки). } \\
\text { Начало очередного цикла на 15-й день }\end{array}$ \\
\hline XELOX & $\begin{array}{l}\text { Оксалиплатин } 130 \text { мг/м² в 1-й день, капецитабин } 2000 \text { мг/м² в сут. 1-14 дни. } \\
\text { Начало очередного цикла на 22-й день }\end{array}$ \\
\hline FLOX & $\begin{array}{l}\text { Оксалиплатин } 85 \text { мг/м² в течение } 2 \text { часов (дни 1; } 15 \text { и } 29 \text { каждого цикла) + } \\
\text { кальция фолинат } 20 \text { мг/м² в/в струйно и с последующим болюсом 5-фторурацил } \\
500 \text { мг/м² еженедельно в течение } 6 \text { нед. с последующим 2-недельным перерывом. }\end{array}$ \\
\hline
\end{tabular}

\section{7. Паллиативная химиотерапия}

3.7.1. Рекомендуется в качестве первой линии терапии у отдельных пациентов с малосимптомным процессом (статус ECOG 0-1), при невозможности назначения в первой линии иринотекана или оксалиплатина, назначать монотерапию (табл. 2) фторпиримидинами. При прогрессировании заболевания рекомендуется рассмотреть возможность добавления к режиму оксалиплатина, а в качестве третьей линии - иринотекана в редуцированных дозах. Для подавляющего числа пациентов рекомендуются к применению в первой линии XT комбинации препаратов (FOLFOX, XELOX или XELIRI, FOLFIRI, FOLFOXIRI) на протяжении не менее 3-4 мес. с последующей возможной поддерживающей терапией фторпиримидинами до прогрессирования. Оксалиплатин в монотерапии малоэффективен и должен применяться в комбинации с фторпиримидинами. При прогрессировании после ранее достигнутого эффекта необходимо рассмотреть вопрос о повторном применении ранее эффективного режима. При микросателлитной нестабильности высокого уровня возможно назначение в первой линии пембролизумаба в монорежиме, комбинации ипилимумаба с ниволумабом.

3.7.2. У пациентов с клинически значимыми симптомами заболевания (ECOG 1-2) с обширной диссеминацией рекомендуется использование в первой линии двойных комбинаций препаратов (FOLFOX, XELOX или XELIRI, FOLFIRI) 
на протяжении не менее 3-4 мес. с последующей возможной поддерживающей терапией фторпиримидинами. В случае прогрессирования опухолевого процесса после первой линии терапии, вторая линия может быть назначена пациентам с удовлетворительным общим статусом (ECOG $\leq 2$ ). При рефрактерности к режиму FOLFOX (XELOX) в качестве второй линии обычно назначают режим FOLFIRI/XELIRI или монотерапию иринотеканом, при рефрактерности к иринотекану в первой линии в режиме FOLFIRI - FOLFOX/XELOX (табл. 4, 5). В случае, если прогрессирование заболевания отмечено после или во время адъювантной XT, оптимальным вариантом первой линии будет являться иринотекан-содержащая XT (FOLFIRI/XELIRI), что по результатам поданализов рандомизированных исследований показывает наилучшие результаты в сравнении с режимом FOLFOX или FOLFOXIRI.

3.7.3. Рекомендуется к вышеперечисленным режимам добавление МКА (бевацизумаб, цетуксимаб или панитумумаб, что увеличивает продолжительность жизни, при условии наличия в клинике лекарственных препаратов). В монотерапии бевацизумаб малоэффективен. Рекомендуется продолжение терапии бевацизумабом с фторпиримидинами до прогрессирования заболевания. В случае дальнейшего прогрессирования возможно продолжение бевацизумаба со сменой режима. На сегодняшний день неизвестны клинические или молекулярные факторы, предсказывающие эффективность бевацизумаба. Наибольшую активность бевацизумаб демонстрирует в первой и во второй линиях терапии; добавление бевацизумаба к режимам на основе оксалиплатина или иринотекана во второй линии лечения достоверно увеличивает продолжительность жизни. Во второй линии терапии возможно применение других антиангиогенных моноклональных антител - афлиберцепта или рамуцирумаба, которые применяются только в сочетании с режимом FOLFIRI. В отличие от бевацизумаба моноклональные анти-EGFR антитела (цетуксимаб и панитумумаб) активны как в монотерапии, так и в комбинации с XT. Анти-EGFR антитела не должны применяться с капецитабином, режимами FLOX, XELOX. Самостоятельная активность цетуксимаба и панитумумаба позволяет рекомендовать их в монотерапии у пациентов и в третьей - четвертой линии. Совместное применение бевацизумаба и анти-EGFR антител ухудшает результаты лечения и не рекомендуется. При микросателлитной нестабильности высокого уровня в первой линии возможно назначить пембролизумаб в монорежиме или комбинацию ипилимумамба с ниволумабом. Сроки начала XТ первой линии должны быть в рамках 28 дней с момента установки диагноза метастатического рака или удаления первичной опухоли при метастатическом раке.

3.7.4. Задачи паллиативной ХT - увеличение продолжительности жизни, уменьшение симптомов болезни и улучшение качества жизни. Пациенты, получившие все три активных химиопрепарата (иринотекан, оксалиплатин и фторпиримидины), имеют достоверно большую продолжительность жизни. При этом не важно, за сколько линий терапии это удается реализовать. До сих 
пор четко не ясна оптимальная продолжительность первой линии терапии. Возможные варианты:

1) непрерывная терапия до прогрессирования заболевания или развития неприемлемой токсичности;

2) проведение лечения на протяжении не менее полугода с последующим наблюдением;

3) применение двойной комбинации в течение не менее 3-4 мес. с последующей поддержкой фторпиримидинами (стратегия «поддерживающей» терапии имеет преимущества перед полным прекращением лечения). В случае применения комбинации ХT с бевацизумабом, поддерживающая терапия бевацизумабом + фторпиримидинами должна проводиться до появления признаков прогрессирования болезни или неприемлемой токсичности. При использовании комбинации XT с анти-EGFR антителами также рекомендуется поддерживающая терапия комбинацией инфузий кальция фолината, фторурацила и анти-EGFR антител (предпочтительно) или монотерапия антителами до прогрессирования заболевания.

3.7.5. У пациентов с прогрессированием на оксалиплатине, иринотекане и фторпиримидинах, бевацизумабе и анти-EGFR антителах по показаниям возможно назначение регорафениба или трифлуридина типирацила. Рекомендуется начинать терапию регорафенибом в следующем режиме: 80 мг в сутки внутрь 1 неделя, 120 мг в сутки внутрь - 2 неделя, 160 мг в сутки внутрь - 3 неделя, затем - 1 неделя перерыв. Эскалация дозы возможна только при удовлетворительной переносимости препарата.

3.7.6. Во второй и более поздних линиях терапии при наличии у пациента микросателлитной нестабильности в опухоли высокого уровня (MSI-H) возможно назначение монотерапии анти-PD1 антителами - ниволумабом или пембролизумабом в монорежиме или комбинацией ниволумаба и ипилимумаба. Последний вариант характеризуется большей частотой объективных ответов.

3.7.7. Ослабленным пациентам с ECOG > 2 в качестве первой линии рекомендуется малотоксичная монохимиотерапия фторпиримидинами или симптоматическая терапия, а при наличии MSI-H - ниволумаб или пембролизумаб.

3.7.8. Рекомендуется при мутации в гене BRAF в качестве первой линии при удовлетворительном состоянии пациента и при отсутствии противопоказаний назначать режим FOLFOXIRI или FOLFOX/XELOX с добавлением MKA бевацизумаба. При прогрессировании на первой линии при мутации в гене BRAF возможно назначение режима FOLFIRI с афлиберцептом / бевацизумабом / рамуцирумабом или комбинации анти-EGFR антител с BRAF и MEK ингибиторами (табл. 6). Оптимальным назначением следует считать комбинацию ингибиторов BRAF и анти-EGFR моноклональных антител. Добавление к данным препаратам ингибиторов МЕК может быть рассмотрено при большом распространении болезни. При сочетании мутации в гене BRAF и микросателлитной 
нестабильности высокого уровня предпочтение отдается иммунотерапии: комбинации ипилимумаба с ниволумабом или пембролизумабу или ниволумабу в монорежиме.

3.7.9. В третьей и последующих линиях терапии при гиперэкспрессии или амплификации гена HER2 в отсутствие мутаций в генах RAS возможно назначение комбинаций трастузумаба и лапатиниба или трастузумаба и пертузумаба.

Таблица 5. Рекомендуемые режимы с иринотеканом и моноклональные антитела, применяемые в лечении колоректального рака

\begin{tabular}{|c|c|}
\hline FOLFIRI & $\begin{array}{l}\text { Иринотекан } 180 \text { мг/м² 90-минутная инфузия в 1-й день, кальция фолинат } 400 \text { мг/м² } \\
\text { в/в в течение } 2 \text { часов с последующим болюсом фторурацила } 400 \text { мг/м² в/в струйно } \\
\text { и 46-часовой инфузией фторурацила } 2400 \text { мг/м² (по } 1200 \text { мг/м² в сутки). Начало очеред- } \\
\text { ного цикла на 15-й день }\end{array}$ \\
\hline FOLFOXIRI $^{1}$ & $\begin{array}{l}\text { Иринотекан } 165 \text { мг/м² 90-минутная инфузия в 1-й день, оксалиплатин } 85 \text { мг/м² 2-ча- } \\
\text { совая инфузия в 1-й день, кальция фолинат } 200 \text { мг/м² в/в в течение } 2 \text { часов с после- } \\
\text { дующей 46-часовой инфузией фторурацила } 3200 \text { мг/м². Начало очередного цикла на } \\
\text { 15-й день. }\end{array}$ \\
\hline XELIRI $^{1}$ & $\begin{array}{l}\text { Иринотекан 180-200 мг/м² в 1-й день, капецитабин 1600-1800мг/м²/сутки 1-14 дни. } \\
\text { Начало очередного цикла на 22-й день. }\end{array}$ \\
\hline Иринотекан & $\begin{array}{l}\text { Иринотекан 250-300 мг/м² в 1-й день. Начало очередного цикла на 22-й день или } \\
180 \text { мг/м² в 1-й день. Начало очередного цикла на 15-й день }\end{array}$ \\
\hline Бевацизумаб & $\begin{array}{l}\text { 7,5 мг/кг в/в 90-60-30-минутная инфузия каждые } 3 \text { недели, или } 5 \text { мг/кг каждые } 2 \text { неде- } \\
\text { ли (может применяться с любым режимом ХТ метастатического рака толстой кишки) }\end{array}$ \\
\hline Афлиберцепт & $\begin{array}{l}4 \text { мг/кг в/в 1-часовая инфузия каждые } 2 \text { недели (вместе с режимом FOLFIRI во второй } \\
\text { линии терапии) }\end{array}$ \\
\hline Цетуксимаб & $\begin{array}{l}400 \text { мг/м² в/в 1-часовая инфузия в первый день, далее по } 250 \text { мг/м² еженедельно } \\
\text { (может применяться в монорежиме, с иринотеканом, с режимами De Gramont, FOLFOX, } \\
\text { FOLFIRI и FOLFOXIRI при метастатическом раке толстой кишки). Возможно назначение } \\
\text { цетуксимаба в дозовом режиме } 500 \text { мг/м² в/в капельно } 1 \text { раз в } 2 \text { недели }{ }^{2}\end{array}$ \\
\hline Панитумумаб & $\begin{array}{l}6 \text { мг/кг в/в 1-часовая инфузия каждые } 2 \text { недели (может применяться в монорежиме, } \\
\text { с иринотеканом, с режимами De Gramont, FOLFOX, FOLFIRI и FOLFOXIRI при метастатиче- } \\
\text { ском раке толстой кишки) }\end{array}$ \\
\hline Рамуцирумаб & $\begin{array}{l}8 \text { мг/кг в/в 1-часовая инфузия каждые } 2 \text { недели (вместе с режимом FOLFIRI во второй } \\
\text { линии терапии) }\end{array}$ \\
\hline Регорафениб & $\begin{array}{l}160 \text { мг } 1 \text { раз в день внутрь в 1-21 дни, } 1 \text { неделя перерыв или } 80 \text { мг в сутки внутрь - } \\
\text { 1-я неделя, } 120 \text { мг в сутки внутрь - 2-я неделя, } 160 \text { мг в сутки внутрь - 3-я неделя, } \\
\text { затем - } 1 \text { неделя перерыв. Эскалация дозы возможна только при удовлетворительной } \\
\text { переносимости препарата }\end{array}$ \\
\hline $\begin{array}{l}\text { Трифлуридин/ } \\
\text { типирацил } \\
\text { (TAS- 102) }\end{array}$ & $\begin{array}{l}\text { По } 35 \text { мг/м² × } 2 \text { раза в день в 1-5 и 8-12 дни внутрь. Начало очередного курса на } \\
29 \text { день +/бевацизумаб } 5 \text { мг/кг в/в капельно в 1-й день } 1 \text { раз в } 2 \text { недели }\end{array}$ \\
\hline Пембролизумаб & $\begin{array}{l}200 \text { мг в/в капельно } 30 \text { минут каждые } 3 \text { недели или } 400 \text { мг в/в каждые } 6 \text { недель³ (только } \\
\text { при МSI-H) }\end{array}$ \\
\hline Ниволумаб & $\begin{array}{l}240 \text { мг или } 3 \text { мг/кг в/в капельно } 30 \text { минут каждые } 2 \text { недели или } 480 \text { мг в/в каждые } \\
4 \text { недели } \text { (только при MSI-H) }\end{array}$ \\
\hline
\end{tabular}




\begin{tabular}{|c|c|}
\hline $\begin{array}{l}\text { Ниволумаб + } \\
\text { ипилимумаб }\end{array}$ & $\begin{array}{l}\text { Ниволумаб } 3 \text { мг/кг в/в капельно } 30 \text { минут каждые } 3 \text { недели и ипилимумаб } 1 \text { мг/кг } \\
\text { в/в капельно } 30 \text { минут } 1 \text { раз в } 3 \text { недели (4 введения, в дальнейшем продолжается } \\
\text { монотерапия ниволумабом в дозе } 240 \text { мг или } 3 \text { мг/кг в/в капельно } 1 \text { раз в } 2 \text { недели } \\
\text { или } 480 \text { мг в/в капельно } 1 \text { раз в } 4 \text { недели или ипилимумаб } 1 \text { мг/кг в/в капельно } 1 \text { раз } \\
\text { в } 6 \text { недель и ниволумаб } 3 \text { мг/кг в/в капельно } 1 \text { раз в } 2 \text { недели - до прогрессирования или } \\
\text { непереносимой токсичностиㄱ (только при MSI-H) }\end{array}$ \\
\hline $\begin{array}{l}\text { Трастузумаб + } \\
\text { лапатиниб }^{4}\end{array}$ & $\begin{array}{l}\text { Трастузумаб } 4 \text { мг/кг в/в в первый день первого цикла, затем } 2 \text { мг/кг в/в -еженедельно. } \\
\text { Лапатиниб } 1000 \text { мг внутрь ежедневно (только при гиперэкспресии или амплификации НЕR2) }\end{array}$ \\
\hline $\begin{array}{l}\text { Трастузумаб + } \\
\text { пертузумаб }^{4}\end{array}$ & $\begin{array}{l}\text { Трастузумаб } 8 \text { мг/кг в/в - нагрузочная доза в первый день первого цикла, затем } 6 \text { мг/кг } \\
\text { в/в каждые } 21 \text { день. Пертузумаб - } 840 \text { мг в/в нагрузочная доза в первый день первого ци- } \\
\text { кла, затем } 420 \text { мг в/в каждые } 21 \text { день (только при гиперэкспресии или амплификации НЕR2) }\end{array}$ \\
\hline
\end{tabular}

1 Режим характеризуется более высокой, чем FOLFIRI, частотой развития диареи.

Возможность проведения XT \pm таргетной терапии в соответствии с рекомендациями определяется доступностью лекарственных препаратов.

2 Введения цетуксимаба 1 раз в неделю или 1 раз в 2 недели в соответствующих дозах равнозначны по эффективности и переносимости как в монотерапии, так и в комбинациях с химиотерапией.

3 Намомент написания рекомендаций режим/препарат не был зарегистрирован в РФ и не входил в клинические рекомендации, одобренные Минздравом РФ.

4 Режим/препарат зарегистрирован в РФ, но не входит в клинические рекомендации, одобренные Минздравом РФ.

Таблица 6. Режимы, применяемые в лечении колоректального рака с мутацией в гене BRAF во второй и последующих линиях лечения

\begin{tabular}{|c|c|}
\hline FOLFIRI & $\begin{array}{l}\text { Иринотекан } 180 \text { мг/м² 90-минутная инфузия в 1-й день, кальция фолинат } 400 \text { мг/м² } \\
\text { в/в в течение } 2 \text { часов С последующим болюсом фторурацила } 400 \text { мг/м² в/в струйно } \\
\text { и 46-часовой инфузией фторурацила } 2400 \text { мг/м² (по } 1200 \text { мг/м² в сутки). Начало оче- } \\
\text { редного курса на 15-й день. } \\
\text { Возможно добавление бевацизумаба в дозе } 5 \text { мг/кг или афлиберцепта в дозе } 4 \text { мг/кг } \\
\text { или рамуцирумаба } 8 \text { мг/кг в/в капельно в 1-й день каждого курса }\end{array}$ \\
\hline $\begin{array}{l}\text { Иринотекан + } \\
\text { BRAF ингибитор + } \\
\text { цетуксимаб }\end{array}$ & 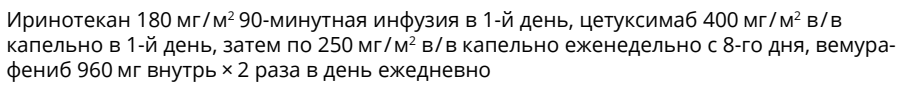 \\
\hline $\begin{array}{l}\text { BRAF + } \\
\text { MEK ингибитор + } \\
\text { панитумумаб }\end{array}$ & $\begin{array}{l}\text { Дабрафениб } 150 \text { мг × } 2 \text { раза в сутки внутрь ежедневно } \\
\text { Траметиниб } 2 \text { мг/сут. внутрь ежедневно } \\
\text { Панитумумаб } 6 \text { мг/кг в/в капельно 1-й день } 1 \text { раз в } 2 \text { недели или цетуксимаб } \\
400 \text { мг/м² в/в капельно } 1 \text { день, затем по } 250 \text { мг/м² в/в капельно еженедельно }\end{array}$ \\
\hline $\begin{array}{l}\text { BRAF+ } \\
\text { MEK-ингибитор } 1\end{array}$ & $\begin{array}{l}\text { Вемурафениб } 960 \text { мг внутрь } 2 \text { раза в день ежедневно и кобиметиниб } 60 \text { мг в день } 3 \text { неде- } \\
\text { ли приема } 1 \text { неделя перерыв }\end{array}$ \\
\hline $\begin{array}{l}\text { BRAF+ } \\
\text { aнmu-EGFR } \\
\text { антитела }\end{array}$ & $\begin{array}{l}\text { Дабрафениб } 150 \text { мг } 2 \text { раза в сутки внутрь ежедневно, панитумумаб } 6 \text { мг/кг в/в ка- } \\
\text { пельно } 1 \text { день } 1 \text { раз в } 2 \text { недели или цетуксимаб } 400 \text { мг/м² в/в капельно } 1 \text { день, затем по } \\
250 \text { мг/м² в/в капельно еженедельно } \\
\text { или } \\
\text { вемурафениб } 960 \text { мг внутрь } 2 \text { раза в день ежедневно, панитумумаб } 6 \text { мг/кг в/в капель- } \\
\text { но } 1 \text { день } 1 \text { раз в } 2 \text { недели или цетуксимаб } 400 \text { мг/м² в/в капельно } 1 \text { день, затем по } \\
250 \text { мг/м² в/в капельно еженедельно }\end{array}$ \\
\hline
\end{tabular}

Возможность проведения XT \pm таргетной терапии в соответствии с рекомендациями определяется доступностью лекарственных препаратов.

1 Режим /nрепарат зарегистрирован в РФ, но не входит в клинические рекомендации, одобренные Минздравом РФ. 


\section{4. СИМПТОМАТИЧЕСКАЯ ТЕРАПИЯ}

4.1. Пациентам с острым кровотечением рекомендуется выполнить срочное эндоскопическое исследование и начать системную гемостатическую терапию. В зависимости от результатов исследования производят эндоскопическую остановку кровотечения. При невозможности / неэффективности эндоскопического гемостаза проводится экстренное хирургическое вмешательство.

4.2. При опухолевом стенозе рекомендуется установка саморасправляющегося стента в зону опухолевого стеноза или оперативное лечение (колостомия / илеостомия).

4.3. При болевом синдроме рекомендуется проведение дистанционной лт, медикаментозной терапии, локорегионарной анестезии в зависимости от причины болевого синдрома.

4.4. При лечении асцита рекомендуется рассмотреть возможность применения диуретиков и лапароцентеза.

4.5. Целью так называемой «наилучшей поддерживающей терапии» является профилактика и облегчение симптомов заболевания и поддержание качества жизни пациентов и их близких, независимо от стадии заболевания и потребности в других видах терапии. В случае РПК меры, направленные на облегчение основных симптомов, способствуют увеличению продолжительности жизни.

\section{5. НАБЛЮДЕНИЕ}

5.1. Основной задачей наблюдения является раннее выявление прогрессирования заболевания с целью своевременного начала ХТ или хирургического лечения резектабельных метастатических очагов, рецидивных опухолей, а также выявление метахронных опухолей ободочной кишки.

5.2. Рекомендуется соблюдать следующую периодичность и методы наблюдения после завершения первичного лечения по поводу РПК: в первые 1-2 года физикальный осмотр и сбор жалоб рекомендуется проводить каждые 3-6 мес., с 3-го по 5-й годы - 1 раз в 6-12 мес. По прошествии 5 лет с момента операции визиты проводятся ежегодно или при появлении жалоб.

5.3. Объем обследования:

- анамнез и физикальное обследование;

- онкомаркер РЭА каждые 3 мес.- в первые 2 года, в последующие 3 года каждые 6 мес.

- колоноскопия - через 1 и 3 года после резекции первичной опухоли, далее - каждые 5 лет для выявления метахронной опухоли или удаления обнаруженных полипов толстой кишки. При выявлении полипов колоноскопия выполняется ежегодно (B). В случае если до начала лечения 
колоноскопия не была выполнена по причине стенозирующей опухоли, ее производят в течение 3-6 мес. после резекции.

- Узи органов брюшной полости и малого таза - каждые 3-6 мес. в зависимости от риска прогрессирования;

- R-графия органов грудной клетки - каждые 12 мес.;

- КТ органов грудной и брюшной полости с в/в контрастированием однократно через 12-18 мес. после операции.

Алгоритм лечебно-диагностических мероприятий при РПК представлен на рис. 1 и в Приложении. 


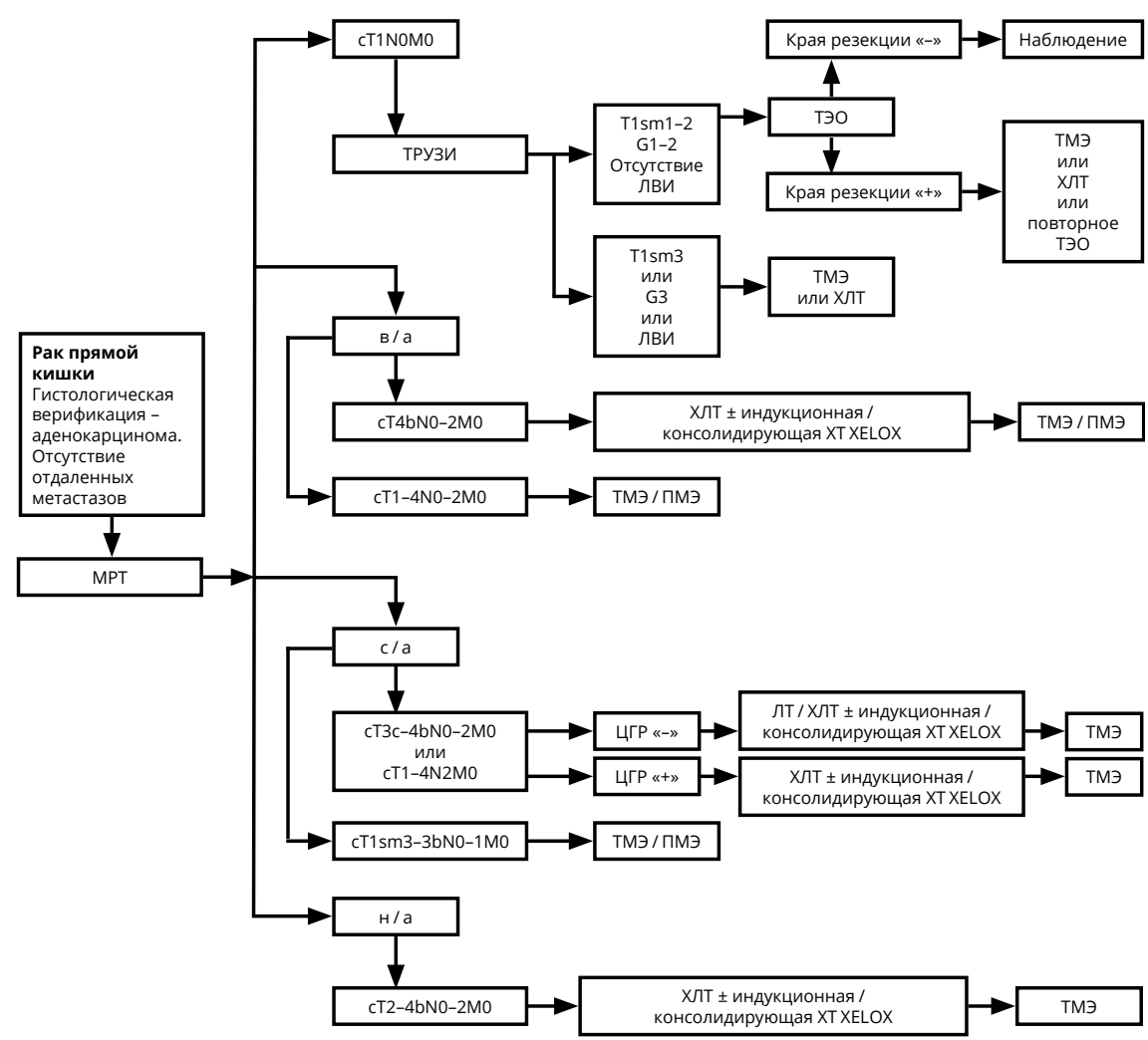

лВИ - лимфоваскулярная инвазия

ТМЭ - тотальная мезоректумэктомия

ПМЭ - парциальная мезоректумэктомия

ЦГР - циркулярная граница резекции

ТЭО - трансанальная эндоскопическая операция

в/а - локализация опухоли в верхне-ампулярном отделе прямой кишки

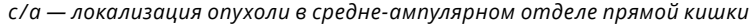

н/a - локализация опухоли в нижне-ампулярном отделе прямой кишки

хлт - химиолучевая терапия.

Рисунок 1. Алгоритм диагностических и лечебных мероприятий при раке прямой кишки без отдаленных метастазов. 


\section{Приложение А. Критерии для генетического обследования пациентов с подозрением на синдром Линча}

КРИТЕРИИ ОТБОРА, РАЗРАБОТАННЫЕ ФГБУ «ГНЦК ИМ. А.Н. РЫЖИХ» ДЛЯ РОССИЙСКИХ ПАЦИЕНТОВ

1. Пациент с колоректальным раком в возрасте до 43 лет.

2. Наряду с колоректальным раком еще 2 случая и более злокачественных опухолей любой локализации у самого больного или у кровных родственников независимо от возраста.

КРИТЕРИИ AMSTERDAM I

1. По крайней мере у 3 родственников присутствует гистологически верифицированный колоректальный рак, один из них - родственник 1-й линии.

2. Заболевание прослеживается по крайней мере в 2 поколениях.

3. По крайней мере у одного из родственников колоректальный рак диагностирован в возрасте до 50 лет.

4. Семейный аденоматозный полипоз исключен.

КРИТЕРИИ AMSTERDAM II

1. По крайней мере у 3 родственников развился рак, связанный с синдромом Линча (колоректальный рак, рак эндометрия, рак желудка, яичников, мочеточника/почечной лоханки, головного мозга, тонкой кишки, гепатобилиарного тракта и кожи (сальных желез)), один из них - родственник 1-й линии.

2. Заболевание прослеживается по крайней мере в 2 поколениях.

3. По крайней мере у одного из родственников связанный с синдромом Линча рак диагностирован в возрасте до 50 лет.

4. Семейный аденоматозный полипоз исключен в случаях наличия колоректального рака.

5. Опухоли по возможности должны быть верифицированы.

КРИТЕРИИ ВЕТНЕSDА ДЛЯ ТЕСТИРОВАНИЯ НА MSІ

1. Колоректальный рак у пациента младше 50 лет.

2. Наличие синхронного, метахронного колоректального рака для другого рака, который может быть связан с синдромом Линча, вне зависимости от возраста.

3. Колоректальный рак с выявленным при гистологическом исследовании высоким уровнем микросателлитной нестабильности (MSI-H) у пациента в возрасте до 60 лет.

4. Колоректальный рак у одного или более родственника 1-й линии с заболеванием, которое может быть связано с синдромом Линча, по крайней мере 1 из случаев заболевания выявлен в возрасте до 50 лет.

5. Колоректальный рак у 2 или более родственников 1-й или 2-й линии с заболеваниями, которые могут быть связаны с синдромом Линча, вне зависимости от возраста. 


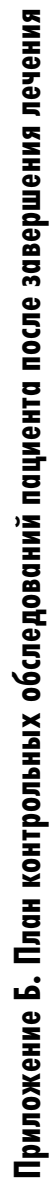

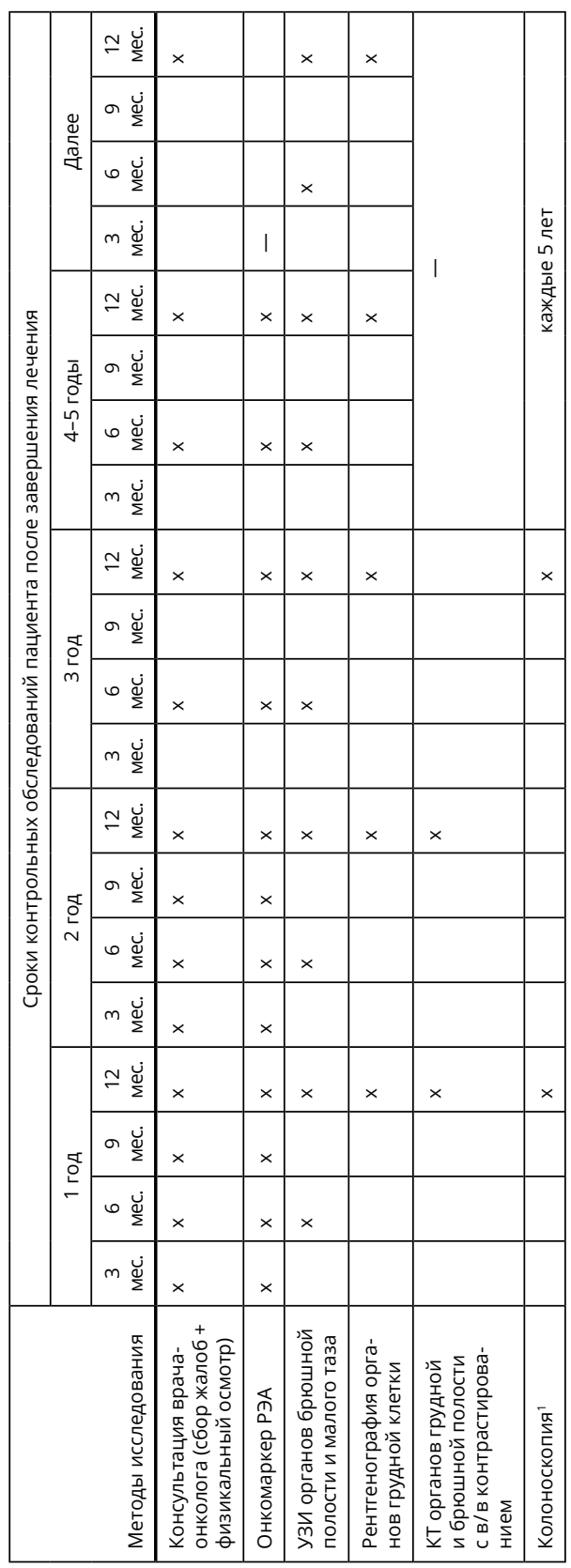

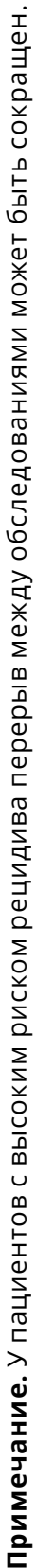

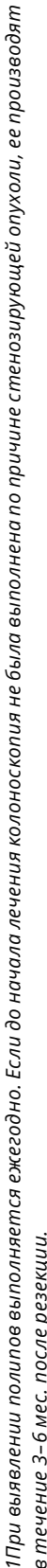




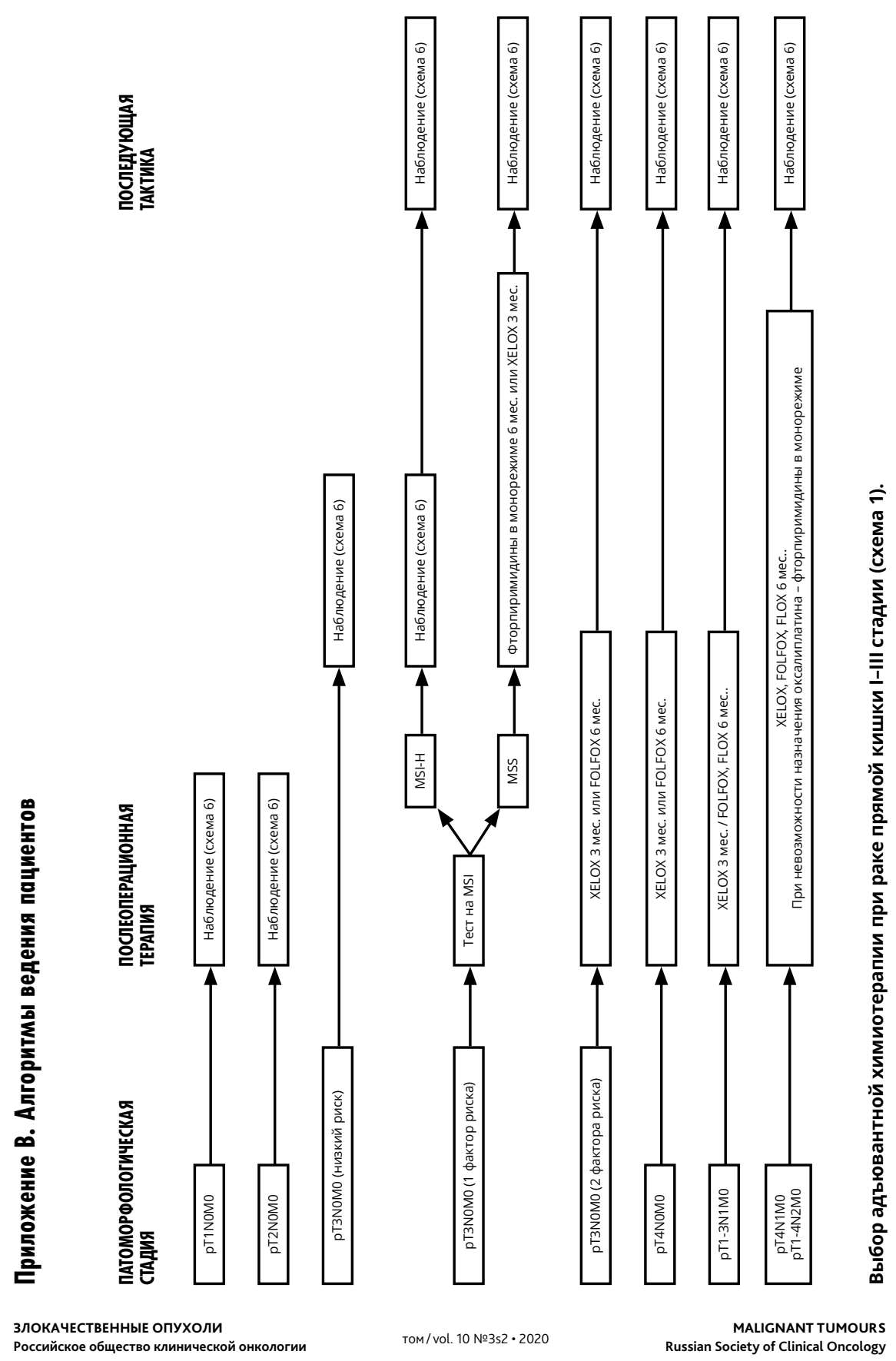




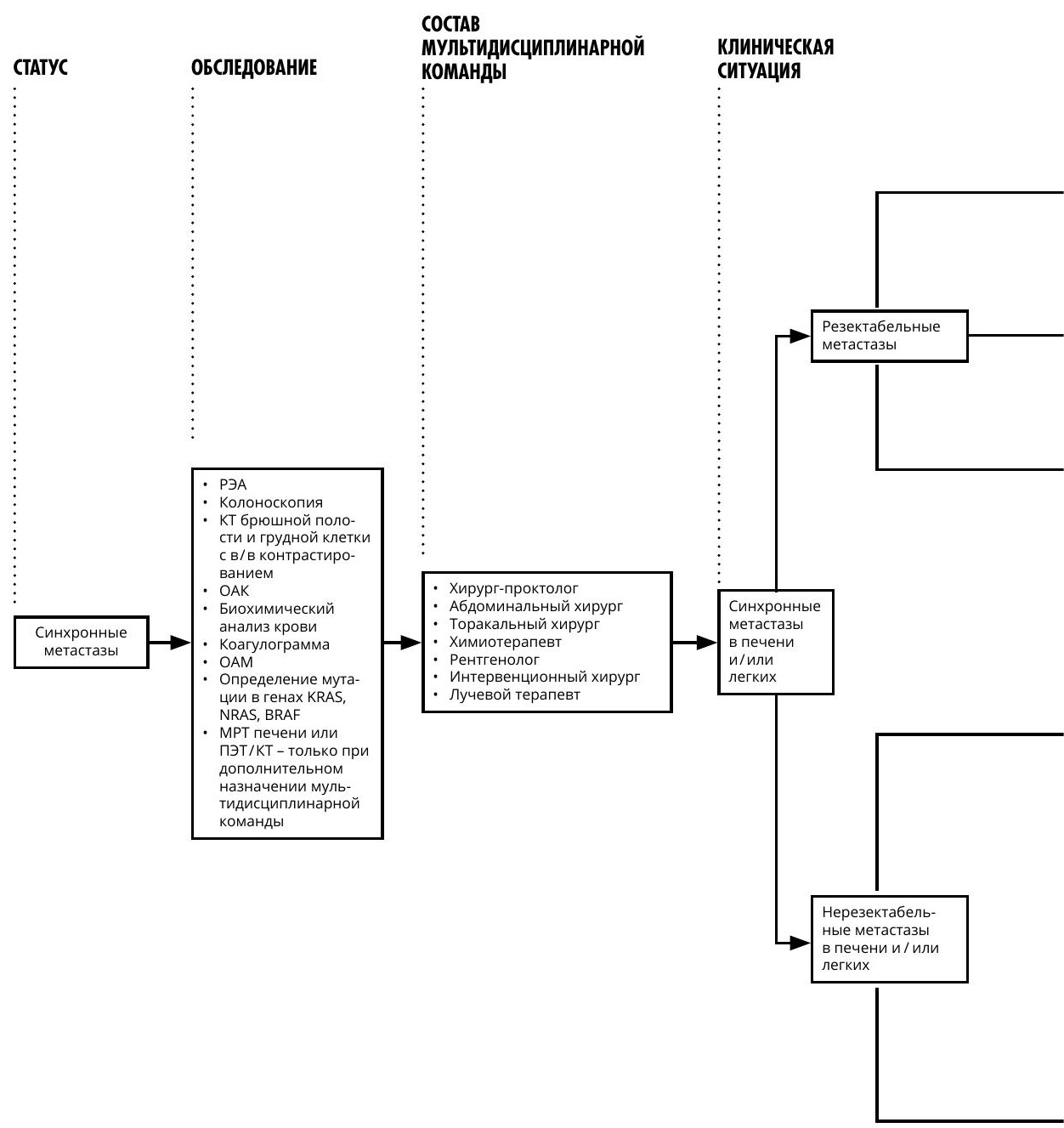


При отсутствии симптомов со стороны первичной опухоли толстой кишки - на 1 этапе можно провести химиотерапию 2-3 месяца по схеме FOLFOX, XELOX, FLOX, фторпиримидины

$$
\vdots
$$$$
\text { : }
$$

Симультанная операция

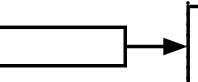

При непереносимости одномоментной операции на толстой кишке и органе, пораженном метастазами - на 1 этапе можно выполнить удаление первичной опухоли
При отсутствии симптомов со стороны первичной опухоли толстой кишки - на 1 этапе проводится химиотерапия 2 месяца по схеме FOLFOX, XELOX/FOLFIRI/FOLFOXIRI \pm бевацизумаб

или

FOLFOX/FOLFIRI/FOLFOXIRI + цетуксимаб/панитумумаб при диком типе генов KRAS, NRAS, BRAF и потенциально операбельных метастазах (локализация первичной опухоли не имеет значения)

При наличии симптомов со стороны первичной опухоли толстой кишки - на 1 этапе проводится удаление первичной опухоли и назначается химиотерапия по схеме FOLFOX XELOX/FOLFIRI/FOLFOXIRI \pm бевацизумаб или

FOLFOX/FOLFIRI/FOLFOXIRI + цетуксимаб/панитумумаб при диком типе генов KRAS, NRAS, BRAF и потенциально операбельных метастазах (локализация первичной опухоли не имеет значения)
Симультанная или последовательная операция на толстой кишке и резекция органов с метастазами или локальная терапия метастазов

Назначение адъювант ной химиотерапии (схема 3)

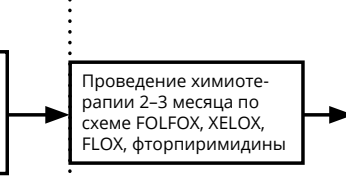
с метастазами или локальная терапия метастазов
Назначение адъювантной химиотерапии (схема 3) 


\section{ЛЕЧЕНИЕ \\ ПОСЛЕОПЕРАЦИОННАЯ \\ TAКТИКА}

Хирургия

FOLFOX, XELOX, FLOX, фторпиримидины

(менее предпочтительны) в монорежиме в течение 6 месяцев

Предоперационная химиотреапия 2-3 месяца по схеме FOLFOX, XELOX, FLOX

FOLFOX, XELOX, FLOX суммарно с предоперационным этапом в течение 6 месяцев

\section{Выбор адъювантной терапии при резектабельных синхронных метастазах (схема 3 ).}

ЛЕЧЕНИЕ

ПОСЛЕОПЕРАЦИОННАЯ

ТАКТИКА

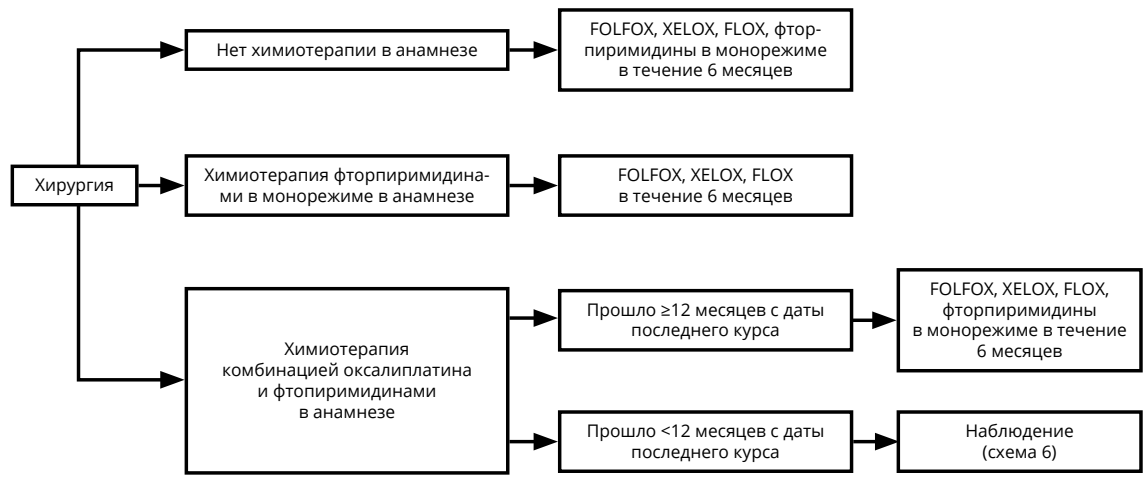

Выбор адъювантной терапии при резектабельных метахронных метастазах (схема 4). 


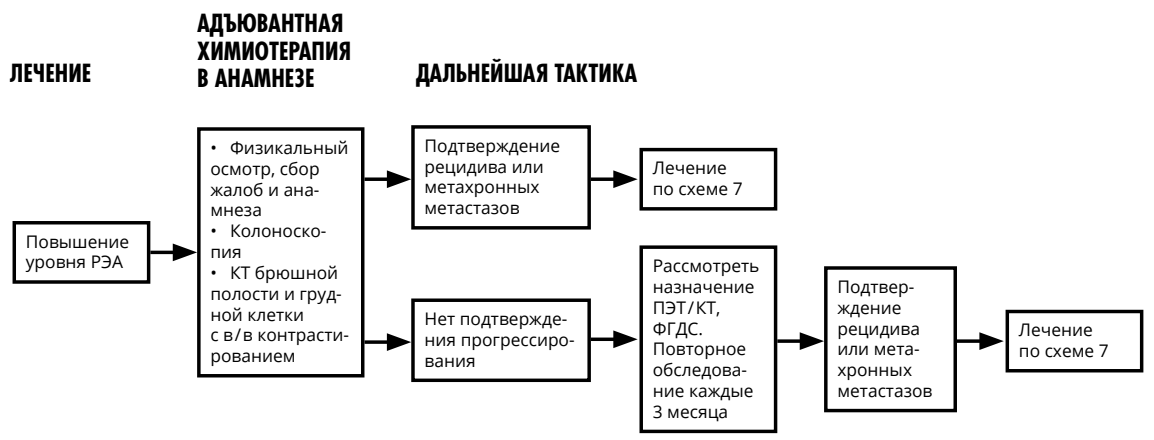

Тактика при подозрительных находках

при наблюдения (схема 5). 


\section{Схема наблюдения за пациентами (схема 6)}

\begin{tabular}{|c|c|}
\hline Лечение & План обследования \\
\hline Стадия I & Колоноскопия \\
\hline \multirow[t]{5}{*}{$\begin{array}{l}\text { Стадия II-III или после радикальной резекции } \\
\text { органов с метастазами }\end{array}$} & Колоноскопия \\
\hline & PЭА \\
\hline & Сбор жалоб, анамнеза, физикальный осмотр \\
\hline & $\begin{array}{l}\text { КТ брюшной полости, грудной клетки, малого таза } \\
\text { с в/в и пероральным контрастированием }\end{array}$ \\
\hline & ПЭТ/КТ не рекомендуется \\
\hline \multirow[t]{6}{*}{ Стадия IV } & Колоноскопия \\
\hline & PЭA \\
\hline & Сбор жалоб, анамнеза, физикальный осмотр \\
\hline & $\begin{array}{l}\text { УзИ брюшной полости, забрюшинного пространства, } \\
\text { малого таза }\end{array}$ \\
\hline & $\begin{array}{l}\text { КТ брюшной полости, грудной клетки, малого таза } \\
\text { с в/в и пероральным контрастированием }\end{array}$ \\
\hline & ПЭТ/КТ не рекомендуется \\
\hline
\end{tabular}


Частота выполнения в 1-ый год

1 раз

Если перед хирургическим лечением не удалось осмотреть все отделы ободочной кишки, необходимо провести полноценную колоноскопию в течение 3-6 мес. от даты операции

1 раз

Если перед хирургическим лечением не удалось осмотреть все отделы ободочной кишки - провести полноценную колоноскопию в течение 3-6 мес. от даты операции

1 раз в 3 мес.

1 раз в 3 мес.

1 раз в 6-12 мес.

\section{Дальнейшее предоставление услуги}

При аденомах - повторить через 1 год; при отсутствии аденом - повторить через 3 года; в дальнейшем при отсутствии патологии - 1 раз в 5 лет

При аденомах - повторить через 1 год; при отсутствии аденом - повторить через 3 года; в дальнейшем при отсутствии патологии - 1 раз в 5 лет

При аденомах - повторить через 1 год; при отсутствии аденом - повторить через 3 года, в дальнейшем, при отсутствии патологии - 1 раз в 5 лет

При аденомах - повторить через 1 год; при отсутствии аденом - повторить через 3 года, в дальнейшем, при отсутствии патологии - 1 раз в 5 лет

1 раз в 3 мес. в течение 2-го года, затем - каждые 6 мес. на протяжении 3-5 лет наблюдения

1 раз в 3 мес. в течение 2-го года, затем - каждые 6 мес. на протяжении 3-5 лет наблюдения

1 раз в 6 мес. в течение 2-го года, затем - 1 раз в год в течение 3-5 лет
При аденомах - повторить через 1 год; при отсутствии аденом - повторить через 3 года, в дальнейшем, при отсутствии патологии - 1 раз в 5 лет

Если перед хирургическим лечением не удалось осмотреть все отделы ободочной кишки, необходимо провести полноценную колоноскопию в течение 3-6 мес. от даты операции

1 раз в 3 мес.

1 раз в 3 мес.

1 раз в 3 мес.

1 раз в 6 мес.
При аденомах - повторить через 1 год; при отсутствии аденом - повторить через 3 года, в дальнейшем, при отсутствии патологии - 1 раз в 5 лет

1 раз в 3 мес. на втором году, затем - каждые 6 мес. на протяжении 3-5 лет наблюдения

1 раз в 3 мес. на втором году, затем - каждые 6 мес. на протяжении 3-5 лет наблюдения

1 раз в 3 мес. на втором году, затем - каждые 6 мес. на протяжении 3-5 лет наблюдения

1 раз в 6 мес. на втором году, затем - 1 раз в год на протяжении 3-5 лет наблюдения 


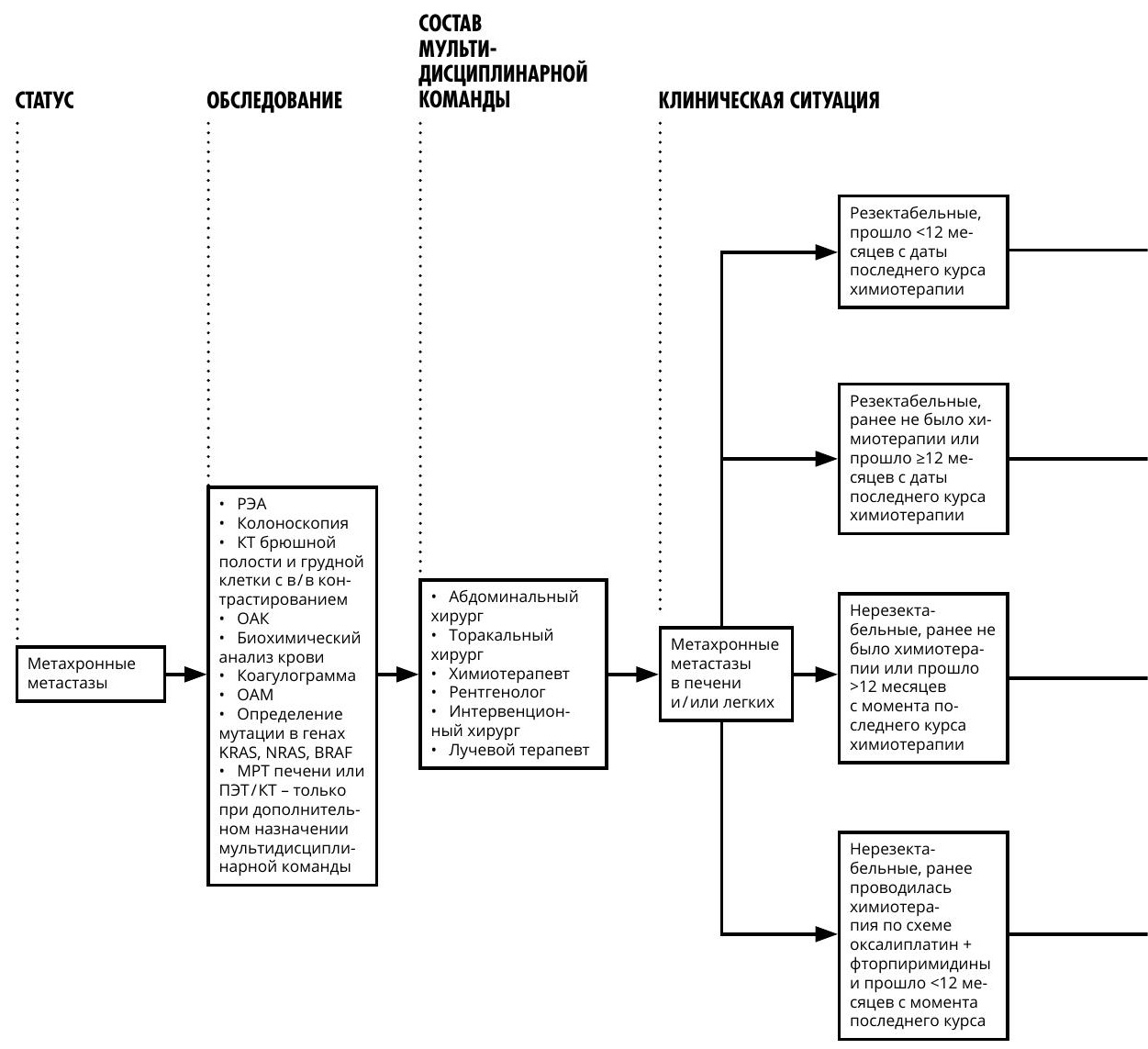

Тактика лечения при метахронных метастазах рака прямой кишки (схема 7). 
1 ЭТАП

Резекция метастазов

Лечение по схеме 2

Проводится химиотерапия 2 месяца по схеме FOLFIRI/иринотекан \pm бевацизумаб, афлиберцепт

FOLFIRI/иринотекан+ цетуксимаб/панитумумаб при диком типе генов

KRAS, NRAS, BRAF и потенциально операбельных метастазах (локализация первичной опухоли не имеет значения), при MSI-H - пембролизумаб или комбинация ипилимумаба с ниволумабом

2 ЭТАП

Назначение адъювантной химиотерапии (схема 4)
3 ЭТАП

4 ЭТАП

Назначение адъювантной химиотерапии (схема 4) 


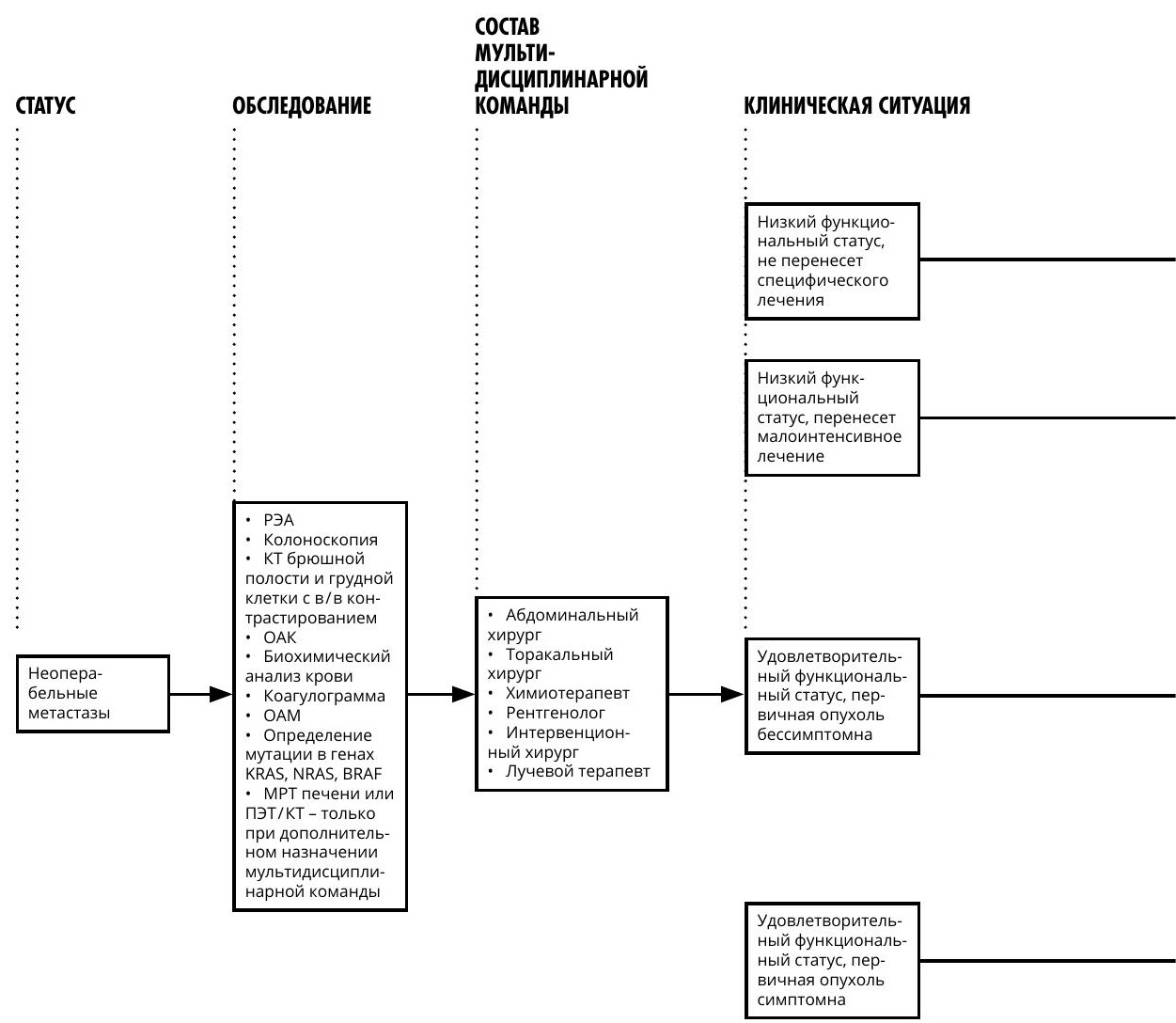

Тактика лечения при неоперабельных метастазах рака прямой кишки (схема 8). 
При улучшении функционального статуса рассмотреть возможность эскалации доз или перехода к стандартным режимам терапии

Оценка эффекта - каждые 2 месяца терапии, при выраженном эффекте и возникновении резектабельных метастазов - обсудить на мультидисциплинарном консилиуме возможности удаления метастазов

См. выше
При осложненном течении первичной опухоли - установка стента

в просвет кишки при угрозе непроходимости или удаление первичной опухоли

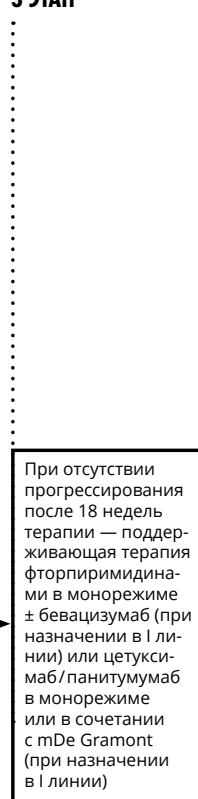

При прогрессировании - выбор ІІ линии (схема 9) 


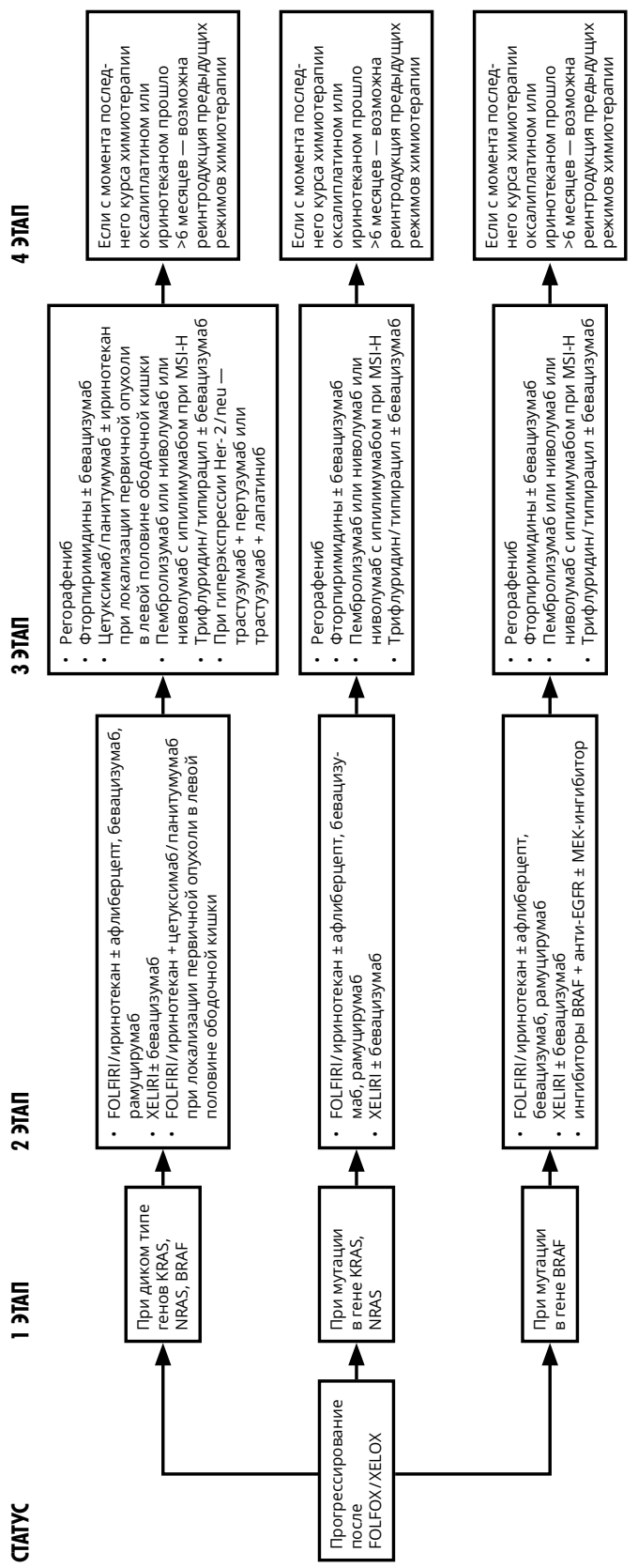

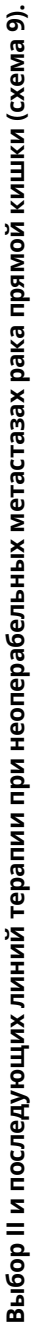




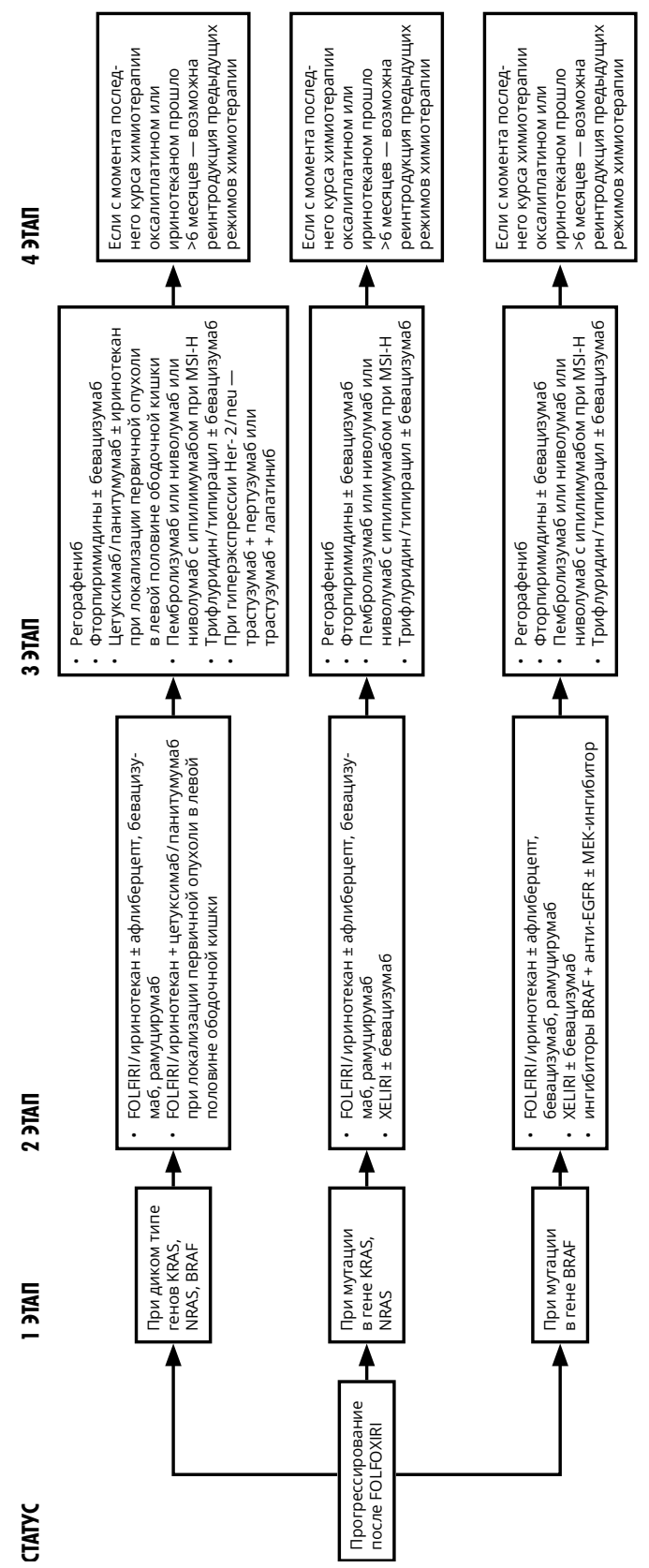

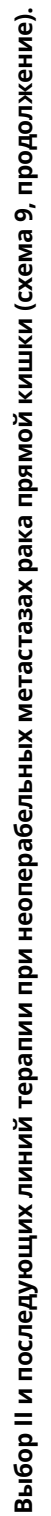




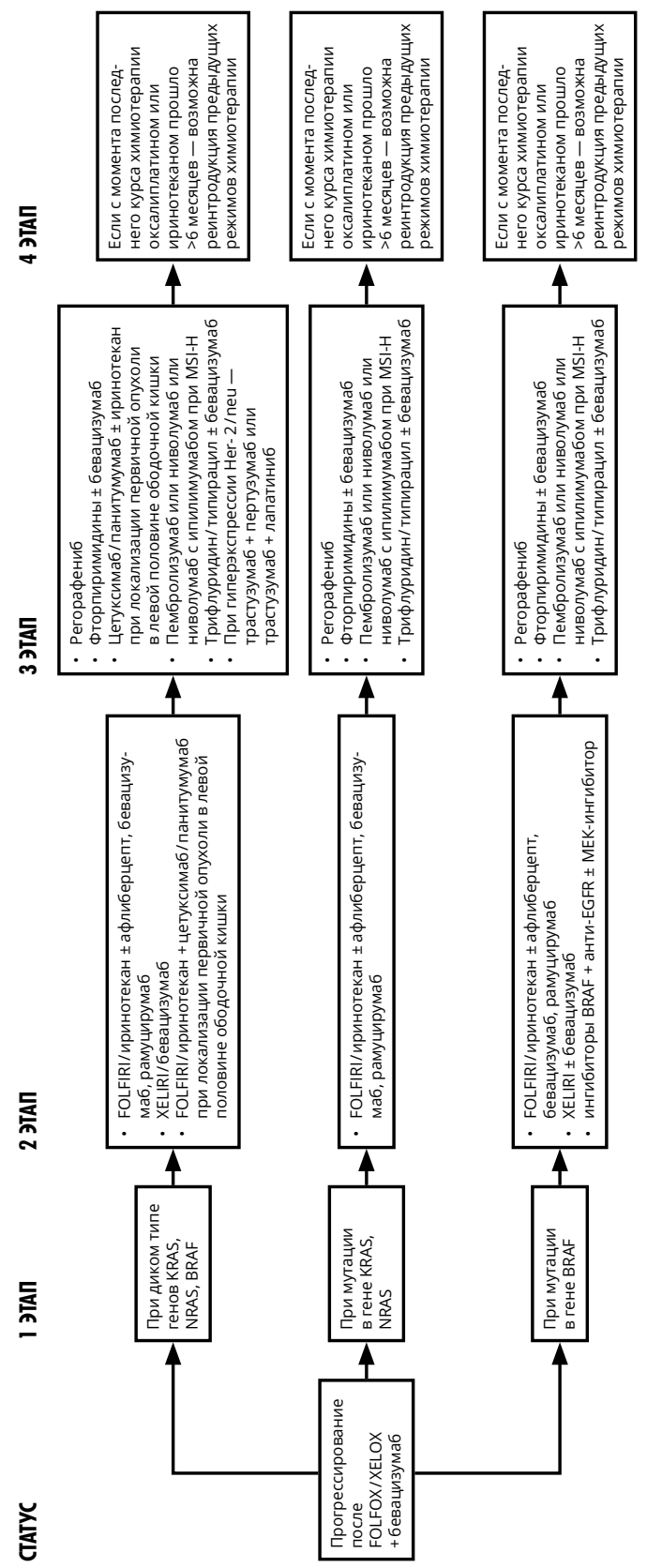

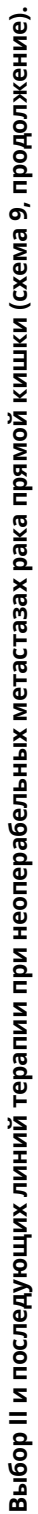




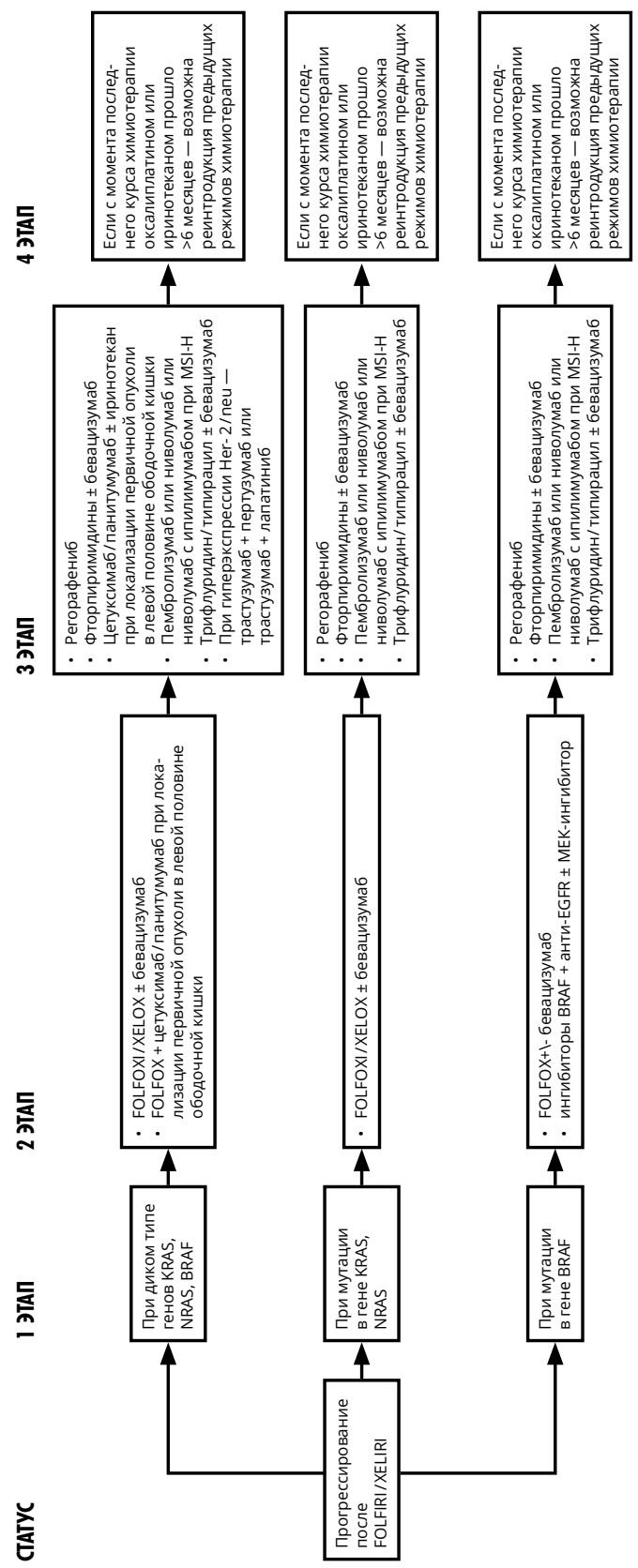

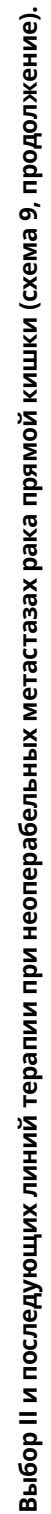




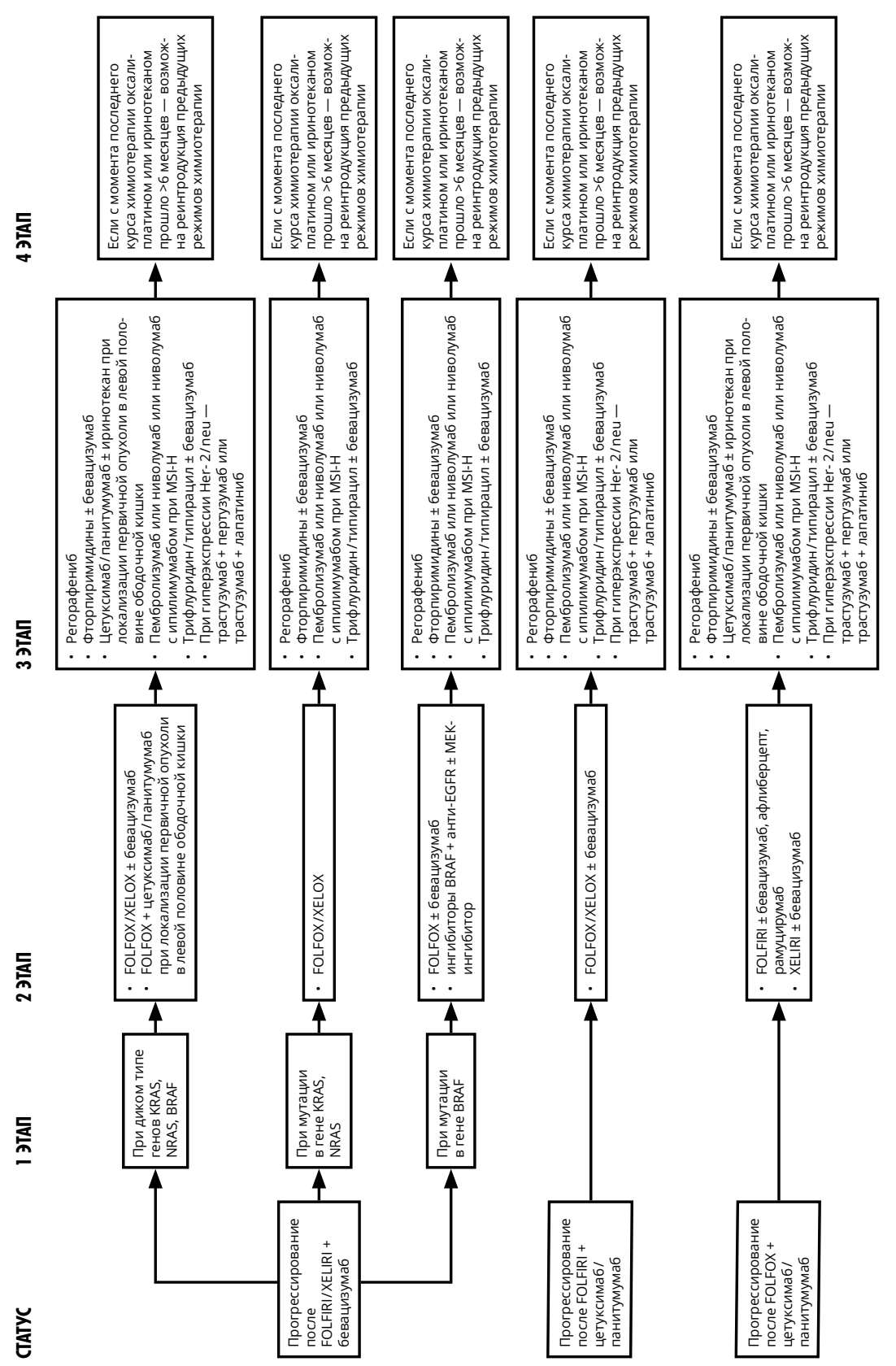

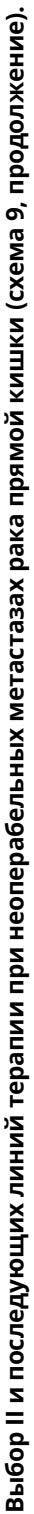

